\title{
Class II phosphoinositide 3-kinase C2 $\beta$ regulates a novel signaling pathway involved in breast cancer progression
}

\author{
Anissa Chikh ${ }^{1, *}$, Riccardo Ferro ${ }^{1, *}$, Jonathan J. Abbott ${ }^{1}$, Roberto Piñeiro ${ }^{1}$, Richard \\ Buus ${ }^{1}$, Manuela Iezzi ${ }^{3}$, Francesca Ricci ${ }^{4}$, Daniele Bergamaschi ${ }^{1}$, Paola Ostano ${ }^{5}$, \\ Giovanna Chiorino5, Rossano Lattanzio ${ }^{2,3}$, Massimo Broggini4, Mauro Piantelli2,3, \\ Tania Maffucci ${ }^{1}$ and Marco Falasca ${ }^{1,6}$ \\ ${ }^{1}$ Queen Mary University of London, Barts and The London School of Medicine and Dentistry, Blizard Institute, Centre for Cell \\ Biology and Cutaneous Research, London, UK \\ 2 Department of Medical, Oral and Biotechnological Sciences, University "G. d'Annunzio", Chieti, Italy \\ ${ }^{3}$ Aging Research Centre (Ce.S.I.), Foundation University "G. d'Annunzio", Chieti, Italy \\ ${ }^{4}$ Laboratory of Molecular Pharmacology IRCCS-Istituto di Ricerche Farmacologiche "Mario Negri", Milan, Italy \\ ${ }^{5}$ Cancer Genomics Laboratory, Fondazione Edo and Elvo Tempia, Biella, Italy \\ ${ }^{6}$ Metabolic Signalling Group, School of Biomedical Sciences, CHIRI Biosciences, Curtin University, Perth, Western Australia, \\ Australia \\ * These authors have contributed equally to this work \\ Correspondence to: Marco Falasca, email: marco.falasca@curtin.edu.au \\ Keywords: breast cancer, cyclinB1, metastasis, miR449, phosphoinositide 3-kinase C2 $\beta$ \\ Received: February 04, $2016 \quad$ Accepted: February 11,2016 Published: February 26, 2016
}

\section{ABSTRACT}

It is now well established that the enzymes phosphoinositide 3-kinases (PI3Ks) have a key role in the development and progression of many cancer types and indeed PI3Ks inhibitors are currently being tested in clinical trials. Although eight distinct PI3K isoforms exist, grouped into three classes, most of the evidence currently available are focused on one specific isoform with very little known about the potential role of the other members of this family in cancer. Here we demonstrate that the class II enzyme PI3K-C2 $\beta$ is overexpressed in several human breast cancer cell lines and in human breast cancer specimens. Our data indicate that PI3K-C2 $\beta$ regulates breast cancer cell growth in vitro and in vivo and that PI3K-C2 $\beta$ expression in breast tissues is correlated with the proliferative status of the tumor. Specifically we show that downregulation of PI3K-C2 $\beta$ in breast cancer cell lines reduces colony formation, induces cell cycle arrest and inhibits tumor growth, in particular in an estrogendependent in vivo xenograft. Investigation of the mechanism of the PI3K-C2 $\beta$ dependent regulation of cell cycle progression and cell growth revealed that PI3K-C2 $\beta$ regulates cyclin B1 protein levels through modulation of microRNA miR-449a levels. Our data further demonstrate that downregulation of PI3K-C2 $\beta$ inhibits breast cancer cell invasion in vitro and breast cancer metastasis in vivo. Consistent with this, PI3KC2 $\beta$ is highly expressed in lymph-nodes metastases compared to matching primary tumors. These data demonstrate that PI3K-C2 $\beta$ plays a pivotal role in breast cancer progression and in metastasis development. Our data indicate that PI3K-C2 $\beta$ may represent a key molecular switch that regulates a rate-limiting step in breast tumor progression and therefore it may be targeted to limit breast cancer spread.

\section{INTRODUCTION}

Regulation of cell proliferation and cell survival in breast cancer is a complex interplay between steroid hormones, growth factors and their receptors [1].
Understanding the signaling pathways involved in these processes may help find predictive factors for tumor aggressiveness and therapy resistance. Among the different pathways activated by growth factors receptors, signals transmitted by the phosphoinositide 3-kinase 
(PI3K)/Akt pathway have proven important for cell survival in many cell types [2]. Several lines of evidence indicate that an inappropriate activation of the PI3K/Akt pathway is linked to the development of cancer and the inhibition of this pathway has been shown to facilitate apoptosis and to sensitize cells to cytotoxic drugs in experimental studies $[3,4]$. It is therefore not surprising that the PI3K/Akt pathway is currently an attractive target for therapeutic strategies. PI3K is a family of enzymes, comprising eight mammalian isoforms grouped into three classes [5]. The majority of studies on PI3K involvement in cancer have been focused so far on members of the class I subfamily. A broad range of tumor types, including breast cancer, are characterized by activating mutations of PIK3CA (the gene encoding for p110 $\alpha$, a member of the class I group) and its downstream effector AKT1, as well as inactivating mutations of phosphatase and tensin homolog $(P T E N)$, the gene encoding the lipid phosphatase that counteracts the action of PI3Ks [6]. Class I PI3Ks, in particular $\mathrm{p} 110 \alpha$, have therefore a well-established role in cancer development and progression. In contrast, the potential role of the class II PI3Ks in cancer has not been fully explored, although accumulating evidence now suggests that this class may also play a role in cancer development [7]. For instance, gene expression profiling has revealed an increased expression of the $\beta$ isoform of the class II group (PI3K-C2 $\beta$ ) in several cancers such as acute myeloid leukemia, glioblastoma and acute lymphocytic leukemia [8-10]. Consistent with this, PI3K$\mathrm{C} 2 \beta$ was found to be overexpressed in subsets of tumor and cell lines from acute myeloid leukemia, glioblastoma multiforme, medulloblastoma and small cell lung cancer [11]. It has also been shown that different small cell lung cancer cell lines overexpress distinct subsets of class IA and II PI3Ks, which results in differences in the signaling cascades activated by stem cell factor [12]. Increased levels of PI3K-C2 $\beta$ have also been detected in primary neuroblastoma tumors and cell lines $[11,13]$. Recently, a significant association has been observed between a cluster of variants located upstream and in the promoter regions of $P I K 3 C 2 B$, the gene encoding for PI3K-C2 $\beta$, and prostate cancer risk, especially for familial, early-onset disease [14]. In addition, significant recurrent mutations (12.9\%) have also been found in $P I K 3 C 2 B$ in lung cancer [15]. Other evidence supporting a role for PI3K-C $2 \beta$ in cancer includes our demonstration that activation of this enzyme is necessary for lysophosphatidic-dependent migration of ovarian and cervical cancer cells [16]. Similarly, it was reported that overexpression of PI3K-C $2 \beta$ enhances migration of A-431 epidermoid carcinoma cells, while overexpression of dominant negative PI3K-C2 $\beta$ reduces this process [17]. More recently, it has been shown that $\mathrm{PI} 3 \mathrm{~K}-\mathrm{C} 2 \beta$ has a key role in neuroblastoma tumorigenesis [18]. Taken together, these data suggested that PI3K-C2 $\beta$ may play a role in cancer development. Interestingly, data also indicated that this isoform may be involved in epidermal growth factor signaling [19], but the precise physiological role of PI3K-C2 $\beta$ in this context and the potential correlation to cancer development have not been investigated.

In this study, we demonstrate that PI3K-C2 $\beta$ is overexpressed in several human breast cancer cell lines and in human breast cancer specimens. Our data indicate that PI3K-C $2 \beta$ regulates breast cancer cell growth and that PI3K-C2 $\beta$ expression in breast tissues is correlated with the proliferative status of the tumor. Furthermore, downregulation of PI3K-C2 $\beta$ inhibits breast cancer cell invasion in vitro and breast cancer metastasis formation in vivo. This establishes PI3K-C2 $\beta$ as a promising target in breast cancer progression and in metastasis development.

\section{RESULTS AND DISCUSSION}

\section{PI3K-C2 $\beta$ is overexpressed in human breast cancer cell lines and regulates breast cancer cell tumorigenesis}

A Western blotting analysis revealed that the expression levels of the class II PI3K isoform PI3K-C2 $\beta$ increased in a panel of breast cancer cell lines compared to epithelial mammary breast cells (BRE80, HBL 100 and MCF10A), suggesting that PI3K-C2 $\beta$ expression is upregulated in breast cancer cell lines compared to 'normal', immortalized breast cells (Figure 1A). To investigate the role of PI3K-C2 $\beta$, we downregulated the levels of the enzyme in human breast cancer cell lines MCF7, T47D and MDA-MB-231 using a specific shRNA (Figure 1B, 1C). Stable cells containing a control, nontargeting shRNA ("sh scrambled") were also generated (Figure 1B, 1C). Western blot analyses confirmed inhibition of $\mathrm{PI} 3 \mathrm{~K}-\mathrm{C} 2 \beta$ protein expression in all cell lines (Figure 1B, 1C). Specifically a strong reduction in PI3K$\mathrm{C} 2 \beta$ levels was obtained in one clone of MCF7 cells (clone 1 , Figure 1B), which was subsequently used for all studies performed in MCF7 cells. Similarly, expression of PI3KC2 $\beta$ was strongly inhibited in T47D and MDA-MB-231 cell populations expressing the specific shRNA (Figure 1C). Importantly, no effect on the levels of the class I PI3K isoforms $\mathrm{p} 110 \alpha, \mathrm{p} 110 \beta$ and the class II enzyme PI3K-C $2 \alpha$ was detected in these cells upon downregulation of PI3KC2 $\beta$ (Figure 1C).

We next investigated the effect of PI3K-C2 $\beta$ downregulation on cell growth. Anchorage-independent growth assessed by soft agar assay was significantly reduced in T47D and MCF7 cells lacking PI3K-C2 $\beta$ (Figure 1D), indicating that this enzyme is required for $3 \mathrm{D}$ growth of these breast cancer cell lines. To evaluate the role of PI3K-C2 $\beta$ in vivo, control MCF7 cells (sh scrambled) and MCF7 lacking PI3K-C2 $\beta$ (sh PI3K-C2 $\beta$ ) were injected orthotopically into the mammary fat pad of 


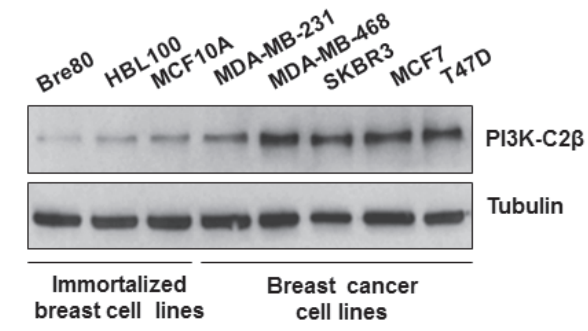

B

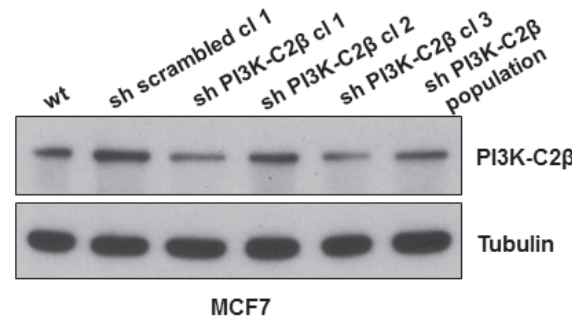

D

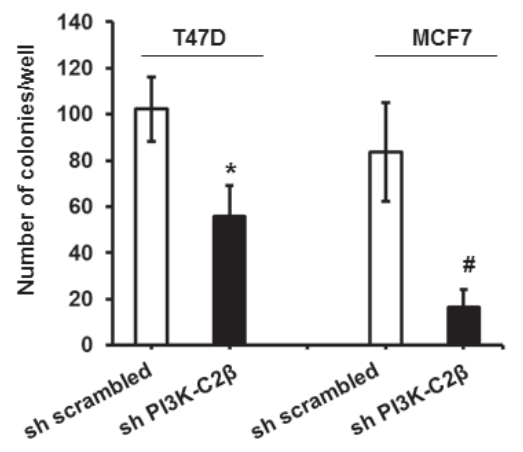

$\mathbf{F}$

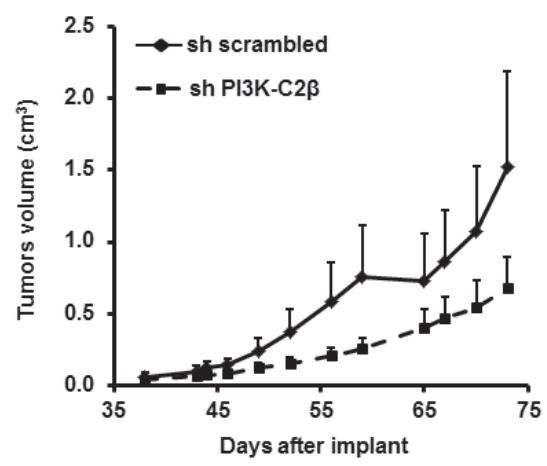

C
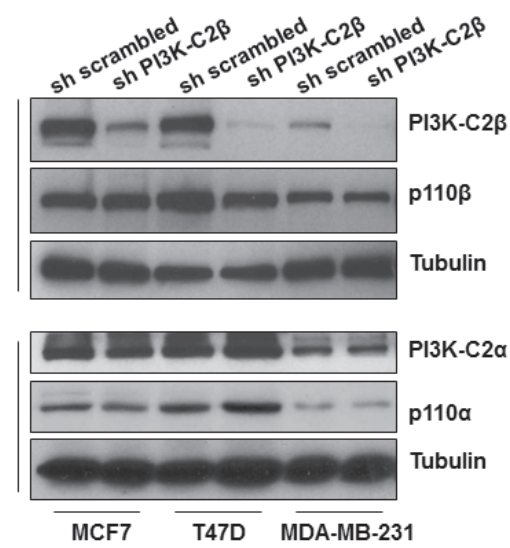

E

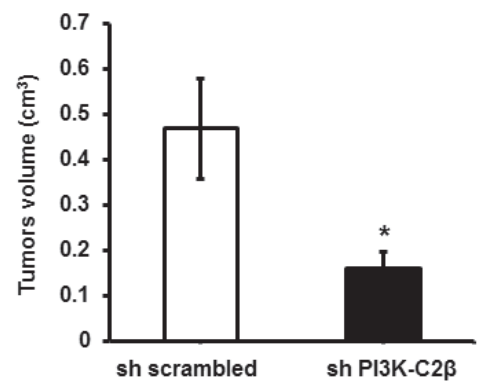

G

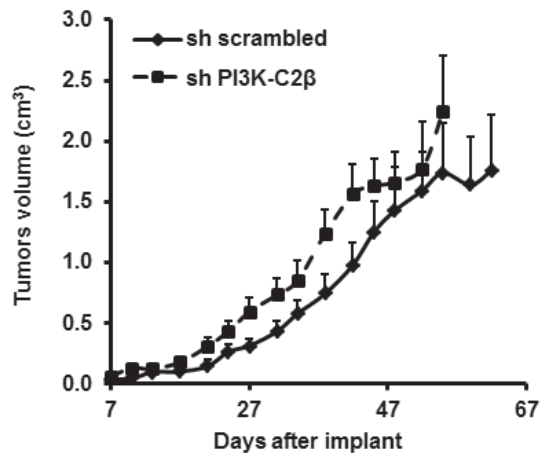

Figure 1: PI3K-C2 $\beta$ is overexpressed in human breast cancer cell lines and plays a critical role in breast cancer cell tumorigenesis. A.Western blot analysis of PI3K-C $2 \beta$ expression in immortalized breast cell lines and in breast cancer cell lines. Tubulin was used as a loading control. B. Expression levels of PI3K-C2 $\beta$ in parental MCF7 (wt) and in the indicated MCF-7 cell lines. Tubulin was used as loading control. C. Levels of p110 $\alpha$, p110 $\beta$, PI3K-C2 $\alpha$ and PI3K-C2 $\beta$ in MCF7, T47D and MDA-MB-231 stable cell lines. In each set of gels, tubulin was used as loading control. D. Results from soft agar colony formation assays performed in the indicated T47D and MCF7 cell lines. Data indicate the number of colonies/well and are means \pm s.e.m. of $n=3$ independent experiments performed in triplicate. ${ }^{*} p=0.025, \# p=0.030$ ( $t$-Test, one tailed distribution, paired). E. The indicated MCF7 cells were diluted in medium+Matrigel ${ }^{\mathrm{TM}}$ and injected into the mammary fat pad of 5 week-old pathogen-free nude mice on day $0 . E_{2}$ pellets were injected subcutaneously into the neck with pellet trochar. Tumors volume was measured after 51 days of implantation. Data are means \pm s.e.m. from $n=6$ (sh scrambled) and $n=16$ (sh PI3K-C2 $\beta$ ) mice. ${ }^{*} p=0.019$ ( $t$-Test, one tailed distribution, two sample unequal variance). F. Control MDA-MB-231 (sh scrambled) and MDA-MB-231 lacking PI3K-C2 $\beta$ (sh PI3K-C2 $\beta$ ) were injected in the mammary fat pad in female immunodeficient mice. Tumor weight was assessed at the indicated days after injection. Values are means \pm SD from 9 mice per group. G. sh scrambled and sh PI3K-C2 $\beta$ MDA-MB-231 cells were injected subcutaneously in female immunodeficient mice. Tumor weight was assessed at the indicated days after injection. Values are means \pm SD from 8 mice per group. 
nude mice treated with estrogen pellets. Data indicated that downregulation of PI3K-C2 $\beta$ significantly reduced tumors volume measured at the end of the experiments (day 51 after implant, Figure 1E). We then injected sh scrambled and sh PI3K-C2 $\beta$ MDA-MB-231 cells in the mammary fat pad of nude mice and followed tumors growth. These data clearly suggested a reduced tumor growth in mice bearing shPI3K-C2 $\beta$ MDA-MB-231 cells compared to mice injected with control cells, although differences did not reach statistical significance possibly because of high variability of tumors volume (Figure 1F). Specifically, at the last day of the experiment (73 days following implant), the weight of tumors generated by sh PI3K-C $2 \beta$ MDAMB-231 was 55\% lower than tumors generated by control cells (Figure 1F). On the other hand growth curves were almost overlapping when the two stable cell lines were implanted subcutaneously in mice, suggesting a potential role for the tumor microenvironment in PI3K-C2 $\beta$ dependent breast cancer development and progression (Figure 1G).

Taken together these data reveal a key role for PI3K$\mathrm{C} 2 \beta$ in breast cancer growth in vitro and in vivo, especially in an estrogen-dependent in vivo xenograft.

\section{PI3K-C2 $\beta$ regulates breast cancer cell proliferation in vitro and cell cycle progression}

To better investigate the specific role of PI3K-C2 $\beta$ in breast cancer cell growth, we assessed the effect of its downregulation in different experimental conditions. Counting of cells in culture incubated in growing media [containing phenol red and 10\% fetal bovine serum (FBS)] indicated that growth of T47D (Figure 2A) and MCF7 (Figure 2B) cells at early passages was not impaired upon downregulation of PI3K-C2 $\beta$. On the other hand, when MCF7 cells were starved in phenol red-free/serum-free media for $24 \mathrm{~h}$ and then stimulated with phenol red/serum free media supplemented with $17 \beta$-Oestradiol $\left(\mathrm{E}_{2}\right)$ - or heregulin B1 (HER), a clear inhibition of cell proliferation was detected in MCF7 lacking PI3K-C2 $\beta$ (Figure 2C, 2D). No difference was observed between parental cells and sh scrambled MCF7 (Figure 2C, 2D). Similarly, cell proliferation induced by HER (Supplementary Figure S1A) and $\mathrm{E}_{2}$ (Supplementary Figure S1B) was impaired in sh PI3K-C2 $\beta$ T47D cells compared to control cells.

To further investigate the specific role of PI3K$\mathrm{C} 2 \beta$, MCF7 cells were synchronized by incubation in phenol red-free/serum-free media for $24 \mathrm{~h}$ followed by incubation in growing media (Figure 2E). Cell cycle analysis indicated that in these experimental conditions downregulation of PI3K-C2 $\beta$ increased the percentage of cells in the G1 phase while reducing the percentage of cells in the G2/M phase of the cell cycle (Figure 2E). No difference was detected between sh scrambled and parental cells (Figure 2E). Similar results were obtained when sh scrambled MCF7 were transiently transfected with a specific siRNA targeting PI3K-C $2 \beta$, incubated in phenol red-free/serum-free media for $24 \mathrm{~h}$ and then in growing media for further $24 \mathrm{~h}$ (Figure $2 \mathrm{~F}$ ) or $48 \mathrm{~h}$ (Figure $2 \mathrm{G})$. Efficient downregulation of PI3K-C $2 \beta$ was confirmed by Western blot (Figure 2H).

These data indicate that $\mathrm{PI} 3 \mathrm{~K}-\mathrm{C} 2 \beta$ regulates HER- and $\mathrm{E}_{2}$-induced cell proliferation and cell cycle progression.

\section{PI3K-C2 $\beta$ regulates cyclin B1 expression}

To gain further insight into the mechanisms of the PI3K-C2 $\beta$-dependent regulation of cell proliferation and cell cycle we then analyzed the activation of several signaling molecules involved in these processes. No effect on the activation of several components of the "classical" class I PI3K pathway, including Akt (Supplementary Figure S2A), 3-phosphoinositide dependent protein kinase 1 (PDK1), and the downstream effectors glycogen synthase kinase (GSK3) $\beta$ (Supplementary Figure S2B), mechanistic target of rapamycin (mTOR) and S6 kinase (S6K) (Supplementary Figure S2C) was detected in MCF7 and T47D cells upon PI3K-C2 $\beta$ downregulation. Importantly, we observed that HER- and insulin-like growth factor-1 (IGF-1)-induced phosphorylation of PDK1, Akt, S6K, GSK3 $\beta$ and ERK1/2 was not affected by PI3K-C2 $\beta$ downregulation in MCF7 and T47D (Supplementary Figure S2D). Similarly, downregulation of PI3K-C2 $\beta$ in these cells did not impair Akt and ERK phosphorylation upon stimulation with insulin, HER and $\mathrm{E}_{2}$ (Supplementary Figure S2E). These data indicate that the reduced proliferation of sh PI3K-C2 $\beta$ MCF7 and T47D upon HER or $\mathrm{E}_{2}$ stimulation is not due to impairment in the activation of MAPK or classical PI3K/Akt pathways. On the other hand, Western blot analysis indicated that downregulation of PI3K-C $2 \beta$ strongly reduced the protein expression levels of cyclin B1 in MCF7 (Figure 3A) and T47D cells (Figure $3 \mathrm{~B}$ ). The effect was specific for cyclin B1 since no reduction in the expression levels of cyclin D1 and cyclin D2 was detected in these cells (Figure 3A, 3B). Reduced levels of cyclin B1 were also observed in MCF7 and T47D upon transient downregulation of PI3K$\mathrm{C} 2 \beta$ using two distinct siRNAs (Figure 3C), ruling out any potential aspecific effect due to the chronic PI3K-C2 $\beta$ downregulation. Furthermore, cyclin B1 but not cyclin D1 protein levels, were also reduced in stable MDA-MB-231 lacking PI3K-C2 $\beta$ (Supplementary Figure S3A).

Taken together these data indicate that PI3K-C2 $\beta$ regulates cyclin B1 expression levels in breast cancer cells. 


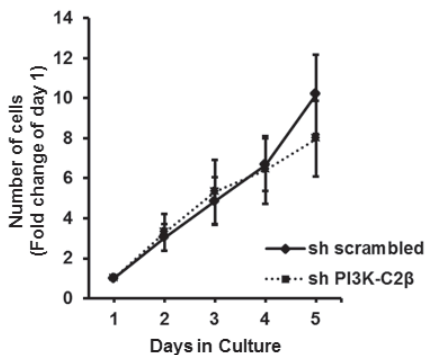

C
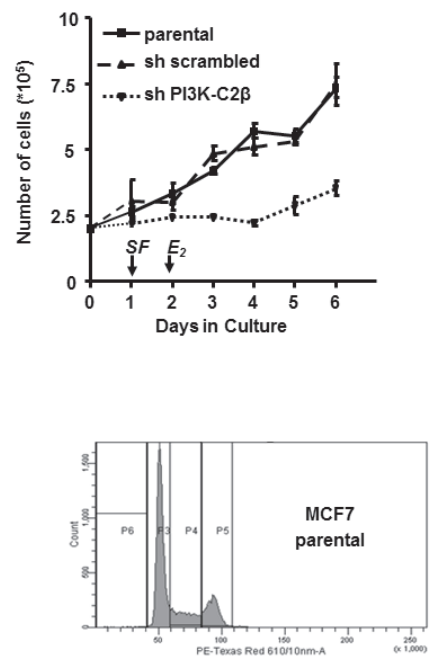

B

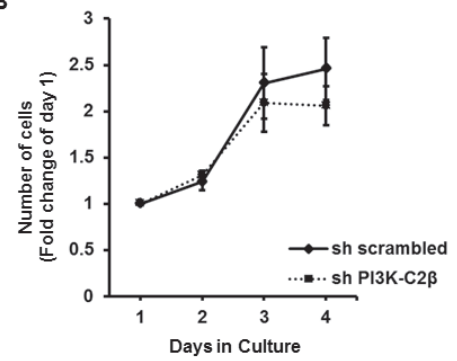

D

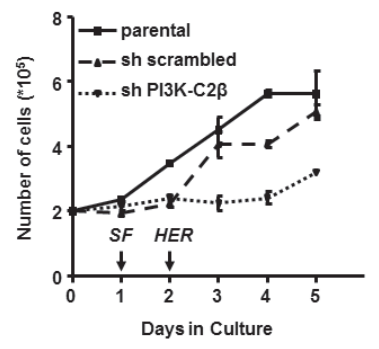

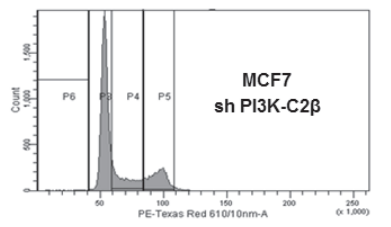

\begin{tabular}{|l|c|c|c|}
\hline & $\begin{array}{c}\text { MCF7 } \\
\text { parental }\end{array}$ & $\begin{array}{c}\text { MCF7 } \\
\text { sh scrambled }\end{array}$ & $\begin{array}{c}\text { MCF7 } \\
\text { sh PI3K-C2 } \beta\end{array}$ \\
\hline subG1 & $0.40 \pm 0.16$ & $0.85 \pm 0.37$ & $1.17 \pm 0.82$ \\
\hline G1 & $44.45 \pm 7.87$ & $44.05 \pm 5.18$ & $61.07 \pm 5.57$ \\
\hline S & $23.90 \pm 2.04$ & $26.35 \pm 3.14$ & $21.30 \pm 1.06$ \\
\hline G2/M & $27.75 \pm 3.55$ & $24.45 \pm 2.25$ & $17.47 \pm 3.25$ \\
\hline
\end{tabular}

$\mathbf{F}$

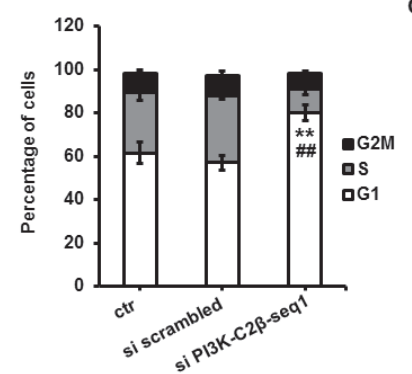

G

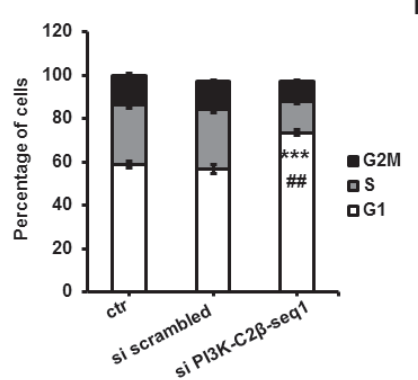

H

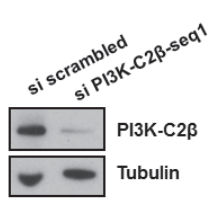

Figure 2: PI3K-C2 $\beta$ regulates breast cancer cell proliferation and cell cycle progression. A., B. The indicated T47D (A) and MCF7 (B) cells were incubated in normal growing media and counted at the indicated days. Data are means \pm s.e.m. from $n=4$ (A) and $n=3$ (B, except for day $4 n=2$ ) independent experiments. C., D. The indicated MCF7 cell lines were plated in 6 well plates. After $24 \mathrm{~h}$ cells were incubated in phenol red-free/serum free (SF) medium for further $24 \mathrm{~h}$ before incubation in phenol red-free/serum free media containing $10 \mathrm{nM} \mathrm{E}_{2}$ or $50 \mathrm{ng} / \mathrm{ml}$ HER. Cell growth was assessed by cell counting at the indicated days. Data are means \pm s.e.m. from at least $n=3$ independent experiments. E. Results from cell cycle analysis performed by FACS in the indicated cell lines. Data are means \pm s.e.m. from at least $n=3$ independent experiments. F. sh scrambled MCF7 cells were transfected with a non targeting siRNA (si scrambled), siRNA specifically targeting PI3K-C2 $\beta$ or transfection reagent alone (control, ctr). The following day cells were incubated with phenol red-free/serum-free media for $24 \mathrm{~h}$ and then incubated for further $24 \mathrm{~h}$ with growing media. Data indicate results from FACS analysis from $n=4$ independent experiments (apart from si scrambled, $n=3$ ). ${ }^{* *} p=0.0028 v s$ si scrambled ( $t$-Test, one tailed distribution, two sample, unequal variance) \#\#p=0.0084vs control ( $t$-Test, one tailed distribution, paired). G. sh scrambled MCF7 cells were transfected and starved as in F and then incubated for $48 \mathrm{~h}$ with growing media. Data indicate results from FACS analysis from $n=5$ independent experiments.

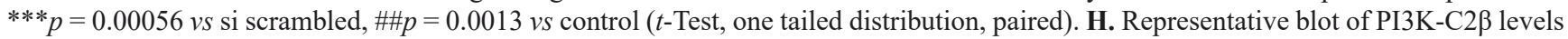
in lysates from sh scrambled MCF7 cells transfected with non targeting siRNA (si scrambled) and a specific siRNA targeting PI3K-C2 $\beta$. Tubulin was used as loading control. 


\section{PI3K-C2 $\beta$ regulates cyclin B1 via miR-449 regulation}

We next sought to assess the mechanism by which PI3K-C2 $\beta$ regulates cyclin B1 expression. The observation that cyclin B1 mRNA levels were not altered in cells lacking PI3K-C2 $\beta$ compared to control cells (Supplementary Figure S3B), led us to hypothesize a potential role for microRNAs (miRs) in the PI3K-C2 $\beta$ dependent regulation of cyclin $\mathrm{B} 1$ expression. To test this hypothesis, we first performed miR expression profiling in the stable T47D cell lines. This analysis revealed a selective upregulation of $16 \mathrm{miRs}$ in T47D cells lacking PI3K-C $2 \beta$ compared to control cells, including $5 \mathrm{miRs}$ belonging to the same family: miR-449a, miR-449b, miR34b, miR-34b*, miR-34c-5p (Figure 3D). Interestingly, members of the miR-34 family have been shown to
A
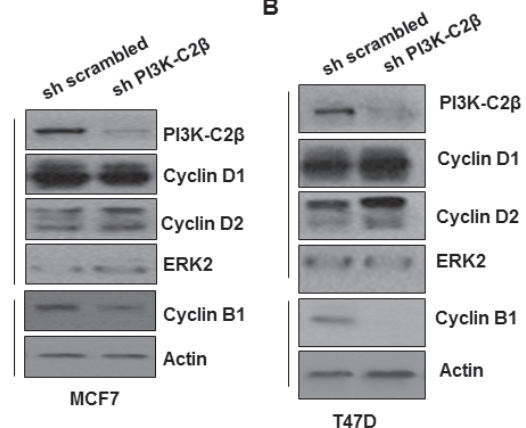

E
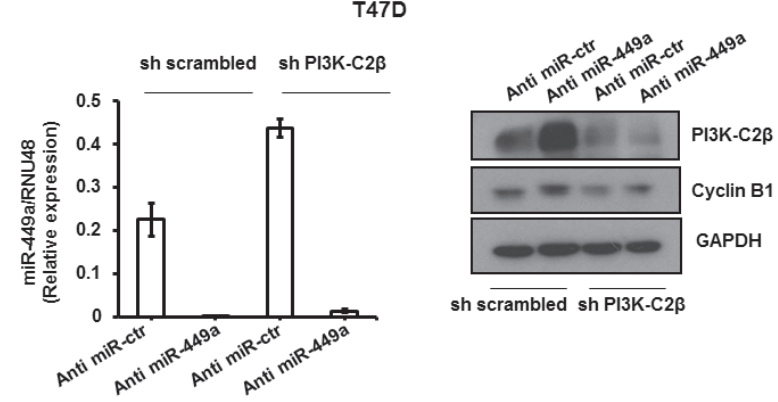

C

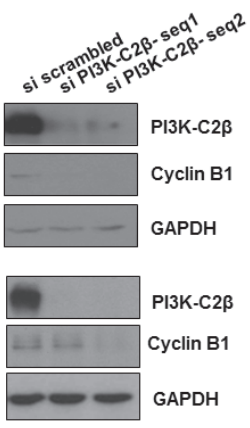

D

\begin{tabular}{|c|c|}
\hline miR & logFc \\
\hline hsa-miR-449a & 0.90 \\
\hline hsa-miR-449b & 2.36 \\
\hline hsa-miR-34b & 1.29 \\
\hline hsa-miR-34b* & 1.33 \\
\hline hsa-miR-34c-5p & 1.47 \\
\hline
\end{tabular}

MDA-MB-231
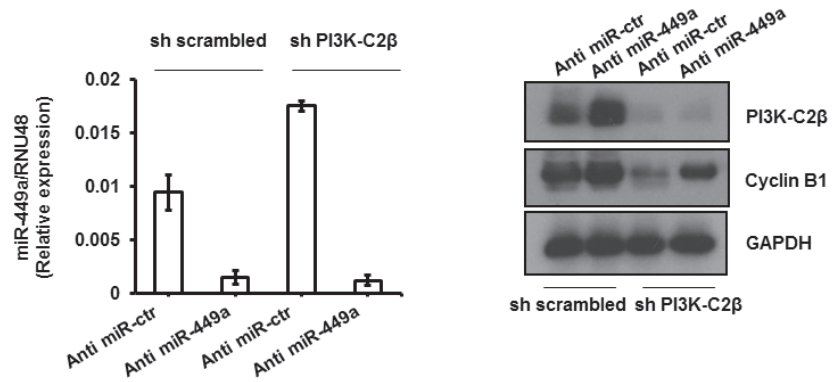

H

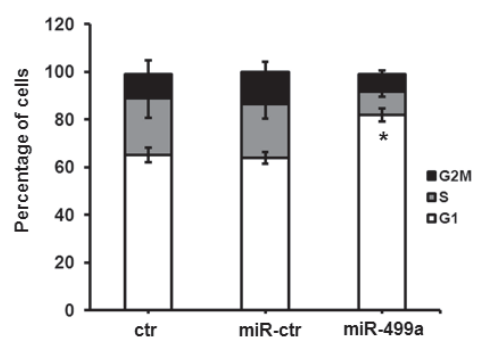

Figure 3: PI3K-C2 $\beta$ regulates cyclin B1 expression through modulation of miR-449a. A., B. Protein expression levels of cyclin D1, cyclin D2 and cyclin B1 in the indicated stable MCF7 and T47D cell lines assessed by Western blotting analysis. Downregulation of PI3K-C2 $\beta$ was also confirmed in these lysates. ERK2 and Actin were used as loading control. C. MCF7 and T47D were transiently transfected with the indicated siRNAs. Efficient downregulation of PI3K-C2 $\beta$ as well as expression levels of cyclin B1 were assessed by Western blotting at $72 \mathrm{~h}$ post transfection. GAPDH was used as loading control. D. Log-fold change (LogFc) values of the indicated miRs as assessed by miRs Array (Agilent platform) showing increased levels in T47D cells lacking PI3K-C2 $\beta$ compared to control, sh scrambled cells. E.-G. The indicated cell lines were transfected with a specific anti miR-449a or a non targeting anti miR (anti miR-ctr). Graphs show levels of miR-449a in the corresponding stable cells at $72 \mathrm{~h}$ following transfection with the indicated anti miRs. Data shown are means \pm \pm s.e.m. from at least $n=3$ independent experiments. Representative Western blots show the protein levels of PI3K-C $2 \beta$ and cyclin B1 in the corresponding cells. GAPDH was used as loading control. H. sh scrambled MCF7 cells were transfected with mimic miR449a (100nM), negative control miR (miR-ctr) or transfection reagent alone (control). Cells were then incubated with phenol red-free/serum free medium for $24 \mathrm{~h}$ before incubation in growing medium for $24 \mathrm{~h}$. Data from FACS analysis are from $n=3$ independent experiments (except for control $n=2) .{ }^{*} p=0.037 v s$ si scrambled ( $t$-Test, one tailed distribution, paired). 
regulate cyclin B1 levels $[20,21]$ therefore, they could potentially be involved in the PI3K-C $2 \beta$-mediated regulation of cyclin B1. To investigate this hypothesis, we first analyzed miRs levels in T47D stable cell lines by q-PCR to validate the results of the array. This analysis not only confirmed a very significant increase in the levels of miR-449a upon PI3K-C2 $\beta$ downregulation, but it also indicated that the levels of this specific miR were much higher than the levels of the other miRs investigated (Supplementary Figure S3C). Upregulation of miR-34b (Supplementary Figure S3D), miR-34c (Supplementary Figure S3E) and miR-449b (Supplementary Figure S3F) was also confirmed in T47D lacking PI3K-C2 $\beta$ compared to control cells, although the levels of these miRs were much lower compared to the levels of miR449-a. Taken together these data indicated that PI3K-C $2 \beta$ regulates miR levels, in particular it down modulates miR-449a levels.

To determine whether the PI3K-C2 $\beta$-mediated regulation of miR-449a was associated with modulation of cyclin $\mathrm{B} 1$ protein expression, we then analyzed the effect of miR-449a downregulation on cyclin B1 expression. Transfection of T47D (Figure 3E), MDA-MB-231 (Figure 3F) and MCF7 (Figure 3G) with a specific anti
miR-449a successfully reduced the levels of miR-449a in all cell lines (graphs in Figure 3E-3G). More importantly, transfection with the specific anti-miR-449a resulted in increased cyclin B1 protein expression, in particular in cells lacking PI3K-C2 $\beta$ (Figure 3E-3G). In addition, transfection of sh scrambled MCF7 cells with miR-449a increased the percentage of cells in G1 phase of the cell cycle assessed upon starvation in phenol red-free/serumfree media and incubation in growing media for $24 \mathrm{~h}$ (Figure $3 \mathrm{H}$ ), consistent with data obtained upon PI3K-C2 $\beta$ downregulation (Figure 2E-2H).

These data indicate that downregulation of PI3K$\mathrm{C} 2 \beta$ reduces cyclin $\mathrm{B} 1$ levels through upregulation of $\mathrm{miR}-449 \mathrm{a}$ and that miR-449a is involved in the regulation of cell cycle progression.

\section{miR-449a levels are downregulated in primary human breast cancer samples}

To determine whether modulation of miR-449a levels occurs in human breast cancer specimens, we analyzed two independent datasets of primary human
A

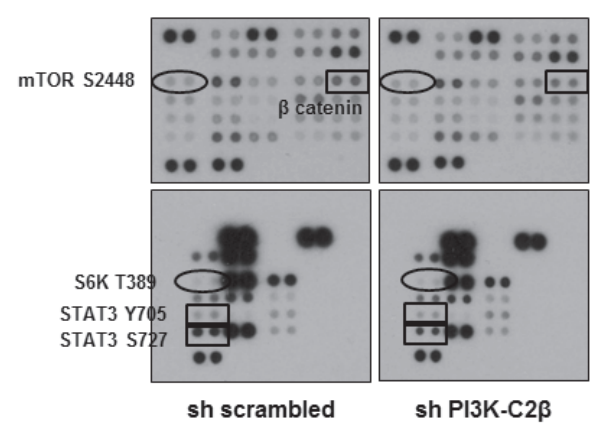

C

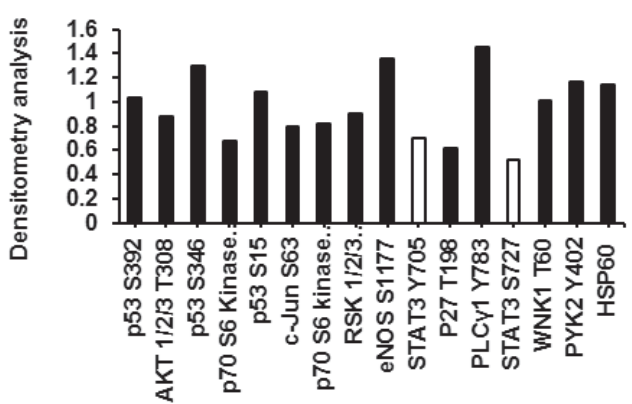

B

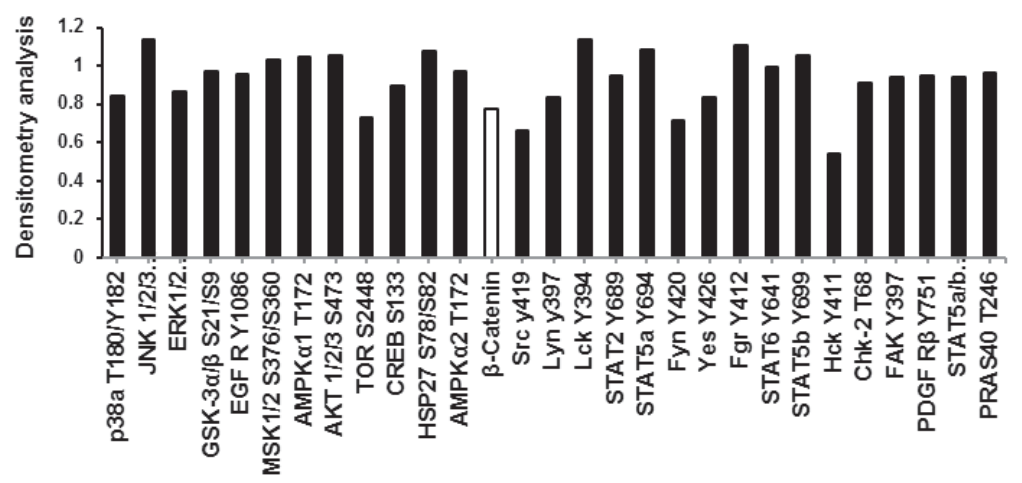

D

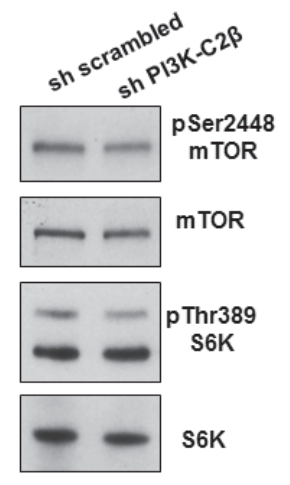

E

$\mathbf{F}$
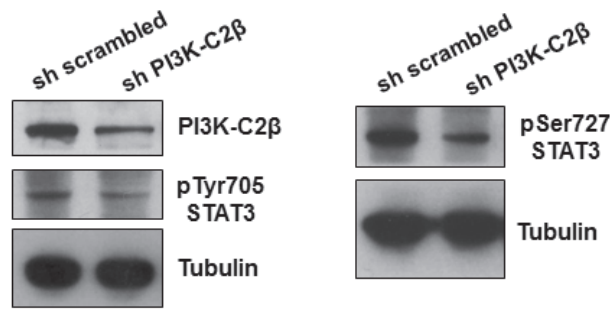

Figure 4: PI3K-C2及 modulates phosphorylation of specific proteins. A. Images from Proteome Profiler Human Phospho-Kinase Array assay performed in stable MDA-MB-231 cells kept in serum. B.,C. Densitometry analysis of the phospho array. For each protein data show values from sh PI3K-C2 $\beta$ samples expressed as fold change compared to corresponding values from sh scrambled samples. D.Western blotting analysis of mTOR and S6K phosphorylation at their residues Ser2448 and Thr389 respectively. Membranes were then stripped and re-incubated with anti mTOR and anti S6K antibodies. E.,F. Western blotting analysis of STAT3 phosphorylation at its residues Tyr705 and Ser727. Tubulin was used as loading control. 
breast cancers, publicly available on Array Express. As shown in Supplementary Table S1, with reference to the E-GEOD-19783 dataset, we observed that the expression of miR-449a was significantly downregulated in basal compared to LUM A and normal-like samples (logFC -0.9 and -0.4 , respectively, $p$-value $<0.01)$, and in TP53 mutated samples versus TP53 wild-type ones (logFC $-0.5, p$-value $<0.01)$. Analysis of the E-GEOD-12848 dataset confirmed the downregulation of miR-449a (Supplementary Table S1) in basal-like samples compared to LUM A ones, and in TP53 mutated versus TP53 wildtype cancers. Additional information on tumor grade revealed that the expression of miR-449a was significantly repressed in grade 3 tumors when compared to grade 1-2 tumors. A similar down-regulation, although not statistically significant, was observed for miR-449a in T3-T4 samples versus T1 ones (Supplementary Table S1). Taken together these data indicate that miR-449a is downregulated in human breast cancer tissues and negatively associated to aggressiveness/progression.

\section{$\beta$ catenin is involved in miR-449a regulation in MDA-MB-231 cells}

To gain further insight into the signaling pathways involved in the PI3K-C2 $\beta$-dependent regulation of miR449a and cyclin B1, we then performed a phosphokinase array, monitoring phosphorylation and activation of $\sim 50$ proteins in the stable MDA-MB-231 cell lines (Figure 4A-4C). Densitometry analysis indicated that downregulation of PI3K-C2 $\beta$ selectively affected phosphorylation/activation of specific proteins (Figure 4B, 4C). Western blotting analysis to validate some of the phosphoarray results revealed only a partial inhibition of mTOR phosphorylation at Ser2448 and no inhibition of S6K phosphorylation at Thr389 in MDA-MB-231 upon downregulation of PI3K-C2 $\beta$ (Figure 4D), consistent with data obtained in MCF7 and T47D (Supplementary Figure S2C). The transcription factor Signal transducer and activator of transcription 3 (STAT3) was amongst the proteins whose phosphorylation was reduced in sh PI3KC2 $\beta$ MDA-MB-231 compared to control cells, according to the results from the phosphoarray (Figure 4C). Further Western blot analysis confirmed that phosphorylation of STAT3 at both Tyr705 and Ser727 was indeed inhibited upon PI3K-C2 $\beta$ downregulation in MDA-MB-231 cells (Figure 4E, 4F). Analysis of the phosphoarray further revealed a specific downregulation of $\beta$ catenin in shPI3K-C2 $\beta$ MDA-MB-231 (Figure 4B). Validation of the phosphoarray by Western blotting analysis confirmed reduced levels of active $\beta$ catenin in MDA-MB-231 lacking PI3K-C2 $\beta$ (Figure 5A). To determine whether the PI3K-C2 $\beta$-dependent regulation of $\beta$ catenin was involved in the regulation of miR-449a and cyclin B1, TRANSFAC was used to identify transcription factors with putative binding sites within $10 \mathrm{~K}$ bases upstream the miR-449a TSS. Factors with either core match and matrix match equal 1 were further selected. 90 putative binding sites were found with core match and matrix match equal 1,35 of which had negative orientation (as miR-449a). Among those 35, 5 corresponded to the transcription factor Lymphoid enhancer-binding factor-1 (LEF1). Since T-cell factor /LEF transcription factors are responsible for the vast majority of $\beta$ catenin signaling outputs $[22,23]$, we then determined whether PI3K-C2 $\beta$ was also involved in LEF1 regulation. Western blotting analysis indicated that LEF1 protein expression levels were indeed downregulated in MDA-MB-231 lacking PI3K-C2 $\beta$ (Figure 5B), suggesting that PI3K-C2 $\beta$ could regulate miR499a by modulating the $\beta$ catenin/ LEF1 pathway. To investigate this hypothesis, we next determined the effect of $\beta$ catenin downregulation on miR-449a levels. Transient downregulation of both $\beta$ catenin and PI3K-C2 $\beta$ in MDA-MB-231 (Figure 5C) significantly increased the levels of miR-449a (Figure 5D). Consistent with the observed upregulation of miR-499a, transient downregulation of $\beta$ catenin reduced cyclin B1 protein levels in MDA-MB-231 (Figure 5E), as observed in cells lacking PI3K-C2 $\beta$ (Supplementary Figure S3A). Furthermore, downregulation of $\beta$ catenin in sh scrambled MDA-MB-231 induced a very slight, albeit significant increase in the percentage of cells in G1 phase of the cell cycle assessed upon starvation in phenol red-free/serumfree media followed by incubation with growing media for 24h (Figure 5F).

Taken together these data indicate that $\beta$ catenin is involved in the PI3K-C2 $\beta$-dependent regulation of miR449a and cyclin B1 levels in MDA-MB-231 cells.

It must be noted that downregulation of $\beta$ catenin (Supplementary Figure S4A) did not affect cell cycle progression in sh scrambled MCF7 cells, assessed following 24h (Supplementary Figure S4B) or 48h (Supplementary Figure S4C) reintroduction of growing media. This would be consistent with reported data indicating a role for $\beta$ catenin in MDA-MB-231 but not in MCF7 cells [24]. We therefore investigated whether STAT3 was involved in the regulation of cell cycle in sh scrambled MCF7 cells. Data showed that downregulation of STAT3 in these cells (Supplementary Figure S4D) did not impair cell cycle progression assessed by FACS analysis upon $24 \mathrm{~h}$ starvation in phenol red-free/serum-free media followed by 24h (Supplementary Figure S4E) or 48h (Supplementary Figure S4F) incubation in growing media. These data indicate that STAT3 does not play a major role in the PI3K-C2 $\beta$-dependent mechanism of cell cycle progression in MCF7 cells. 
A

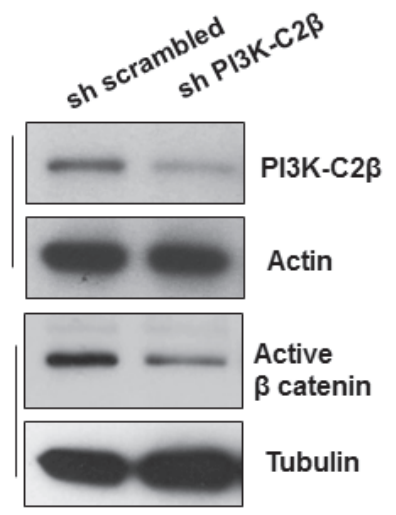

C

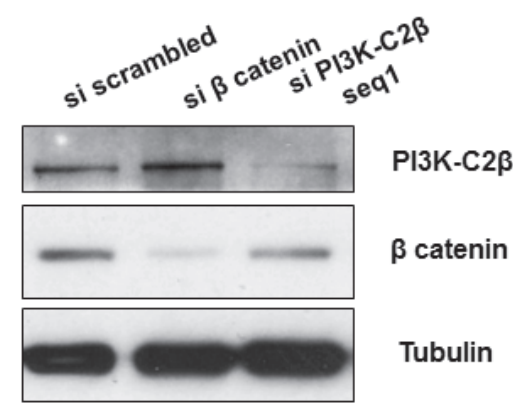

$\mathbf{E}$

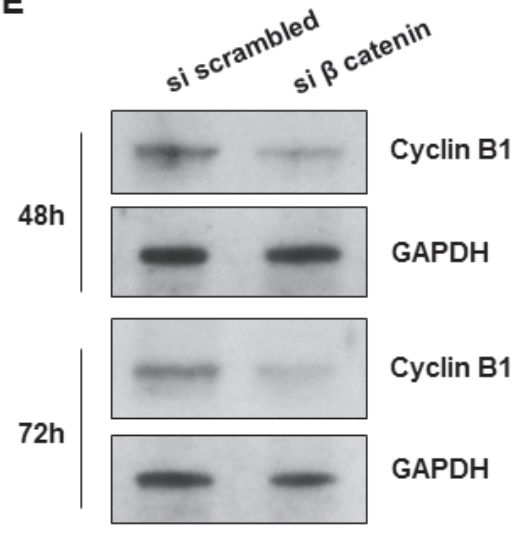

B

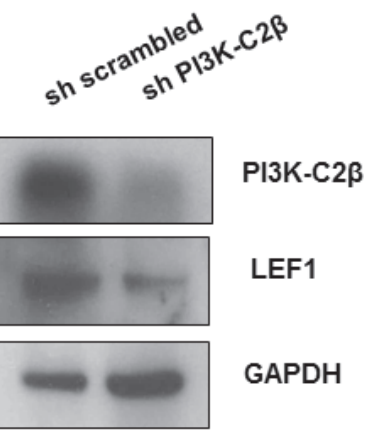

D

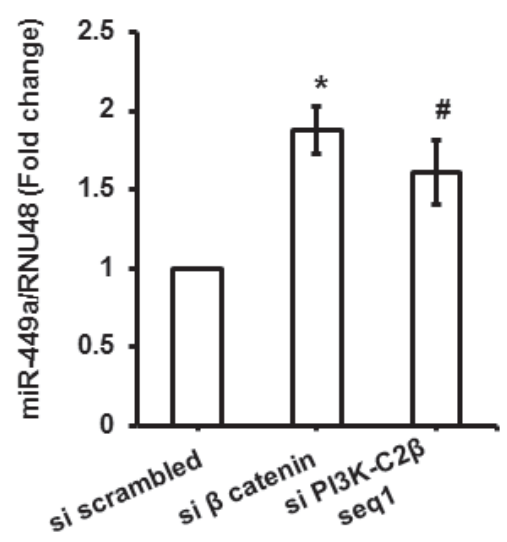

$\mathbf{F}$

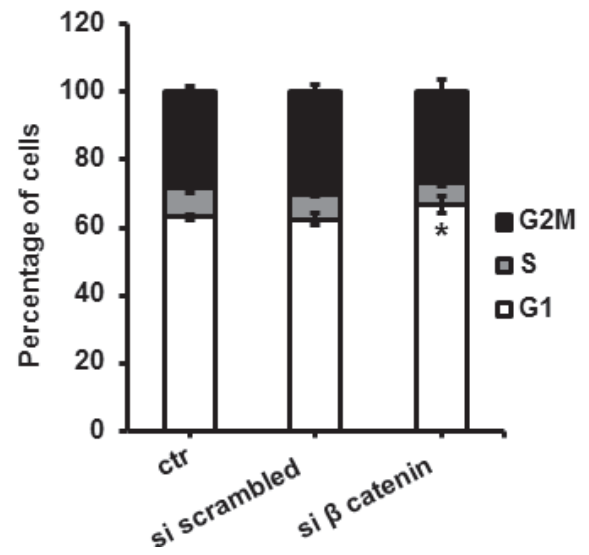

Figure 5: PI3K-C2 $\beta$ regulates miR449a/cyclinB1 through modulation of LEF1/ $\beta$ catenin pathway in MDA-MB-231 cells. A.,B. Western blotting analysis of active $\beta$ catenin (A) and LEF1 protein levels (B) in the indicated MDA-MB-231 stable cell lines. Tubulin was used as loading control and levels of PI3K-C2 $\beta$ were also assessed. C., D. MDA-MB-231 cells were transiently transfected with specific siRNAs targeting $\beta$ catenin and PI3K-C2 $\beta$ respectively. A non targeting (si scrambled) siRNA was used as control. Efficient downregulation of the proteins was determined after 48h. Graph shows the effect of transient transfection with the indicated siRNAs on miR-449a levels. Data are expressed as fold change over miR-449a/RNU48 values in cells transfected with non targeting siRNA and are means \pm s.e.m. of $n=4$ (si scrambled, si $\beta$ catenin) and $\mathrm{n}=3$ (si PI3K-C2 $\beta$ ) independent experiments. ${ }^{*} \mathrm{p}=0.012, \# p=0.026$ ( $t$-Test, one tailed distribution, paired). E. Western blotting analysis of cyclin B1 protein levels in MDA-MB-231 at $48 \mathrm{~h}$ and $72 \mathrm{~h}$ following transfection with the indicated siRNAs. F. MDA-MB-231 cells were transiently transfected as before. Cells were incubated for $24 \mathrm{~h}$ in phenol red-free/ serum-free medium before further incubation for $24 \mathrm{~h}$ in growing medium. Data are means \pm s.e.m. of $n=3$ independent experiments. ${ }^{*} p=$ 0.024 ( $t$-Test, one tailed distribution, paired). 


\section{PI3K-C2 $\beta$ regulates senescence via miR-449 regulation}

It has been recently shown that miR-449 induces cell senescence in prostate and gastric cancer cells $[25,26]$. Interestingly, we observed increased cell size in both MCF7 (Supplementary Figure S5A) and T47D (Supplementary Figure S5B) lacking PI3K-C2 $\beta$. Increased levels of the senescence marker $\beta$-galactosidase were also observed in both cell lines upon PI3K-C2 $\beta$ downregulation (Supplementary Figure S5C) and reduced levels of SIRT1 were detected in MCF7 lacking PI3K-C2 $\beta$ (Supplementary Figure S5D), suggesting that PI3K-C2 $\beta$

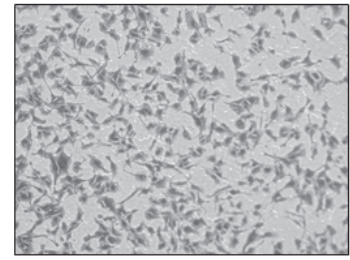

sh scrambled

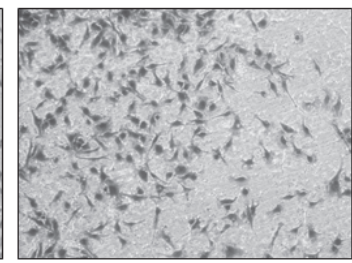

sh PI3K-C2 $\beta$

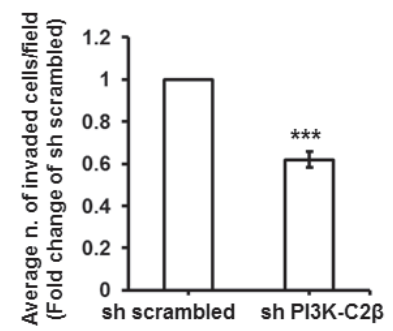

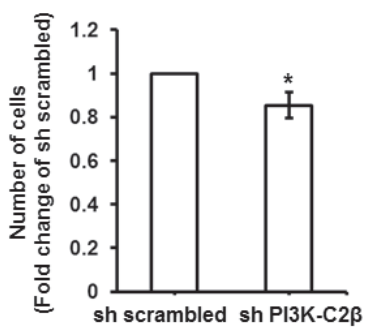

D

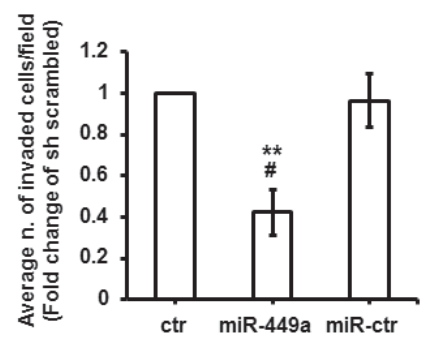

E

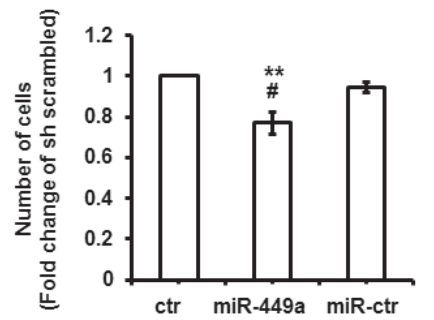

$\mathbf{F}$
G

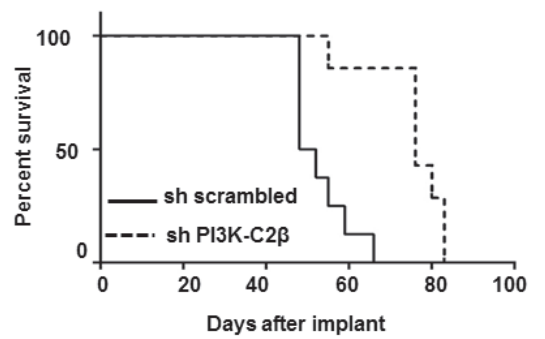

H

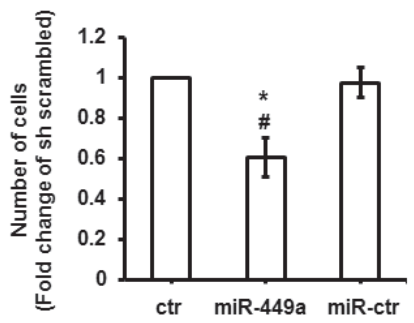

\begin{tabular}{|c|c|}
\hline & $\begin{array}{c}\text { Median survival } \\
\text { (days) }\end{array}$ \\
\hline sh scrambled & 50 \\
\hline sh PI3K-C2 $\beta^{\star}$ & 76 \\
\hline \multicolumn{2}{|c}{${ }^{\star} p=0.0005$}
\end{tabular}

Figure 6: PI3K-C2 $\beta$ regulates cell invasion and metastasis formation. A., B. Representative images and results from invasion assays performed in the indicated stable MDA-MB-231 cell lines. Graph indicates the number of invaded cells/field expressed as fold increase over control (sh scrambled cells) and are means \pm s.e.m. from $n=8$ independent experiments. ${ }^{* * *} p=8.71 * 10^{-6}(t$-Test, one tailed distribution, paired). In these experiments the average number of invaded cells/field was $345 \pm 79$ (sh scrambled) and $214 \pm 52$ (sh PI3K-C2 $\beta$ ). C. Cells were plated as for invasion assays, serum starved overnight and then re-plated for further 48h. Data are expressed as fold change over control (sh scrambled cells) and are means \pm s.e.m. from $n=6$ independent experiments. ${ }^{*} p=0.029(t$-Test, one tailed distribution, paired). D. sh scrambled MDA-MB-231 cells were transfected with mimic miR-449a, negative control miR (miR-ctr) or transfection reagent alone (control, ctr). The following day cells were starved overnight and then detached for invasion assay, as described in the Methods. Graph indicates the number of invaded cells/field expressed as fold increase over control cells and are means \pm s.e.m. from $n=5$ independent experiments (except for miR-ctr, $n=4) .{ }^{* *} p=0.0031 v s$ control ( $t$-Test, one tailed distribution, paired), $\# p=0.029 v s$ miR-ctr ( $t$-Test, one tailed distribution, two sample unequal variance). In these experiments the average number of invaded cells/field was $445 \pm 48$ (control), 207 \pm 80 (miR-449a) and 429 \pm 80 (miR-ctr). E. sh scrambled MDA-MB-231 cells were transfected and starved as in D. Results from cell counting performed at the start of invasion assays, i.e. $48 \mathrm{~h}$ after transfection. Data are expressed as fold change over control cells and are means \pm s.e.m. from $n=5$ independent experiments. ${ }^{*} p=0.0067 v s$ control, $\# p=0.015 v s$ miR-ctr $(t$-Test, one tailed distribution, paired). F. sh scrambled MDA-MB-231 cells were transfected and starved as in D. Results from cell counting performed at the end of the invasion assays. Data are expressed as fold change over control cells and are means \pm s.e.m. from $n=5$ independent experiments (except for miR-449a, $n=4) .{ }^{*} p=0.013 v s$ control, $\# p=0.035 v s$ miR-ctr ( $t$-Test, one tailed distribution, two samples unequal variance). G., H. Survival curve of mice injected intravenously with the indicated stable MDA-MB-231 cell lines. Each group consisted of 8 mice. The median survival in days for the two groups is also shown. The statistical difference in survival $(p=0.0005)$ was calculated using the Log-rank test. 
may have a role in senescence regulation. To determine whether this PI3K-C2 $\beta$-mediated regulation of cellular senescence was dependent on miR-449a regulation, we next investigated the effect of miR-449a downregulation on SIRT1 levels. Data showed that downregulation of miR-449a (performed in parallel with experiments presented in Figure $3 \mathrm{G}$ ) was indeed able to counteract the effect of PI3K-C2 $\beta$ downregulation on SIRT1 levels and to increase SIRT1 protein levels (Supplementary Figure S5D). Furthermore, analysis of cellular proliferation by cell counting showed growth impairment in MCF7 and T47D lacking PI3K-C2 $\beta$ when kept in culture for more than 10 passages (Supplementary Figure S5E, S5F).

\section{PI3K-C2 $\beta$ regulates cell invasion and in vivo metastasis formation}

Data so far indicated that PI3K-C2 $\beta$ has a key role in breast cancer growth both in vivo and in vitro. Since PI3K-C2 $\beta$ has previously been involved in cancer cell migration $[16,17]$, we next investigated the potential role

A

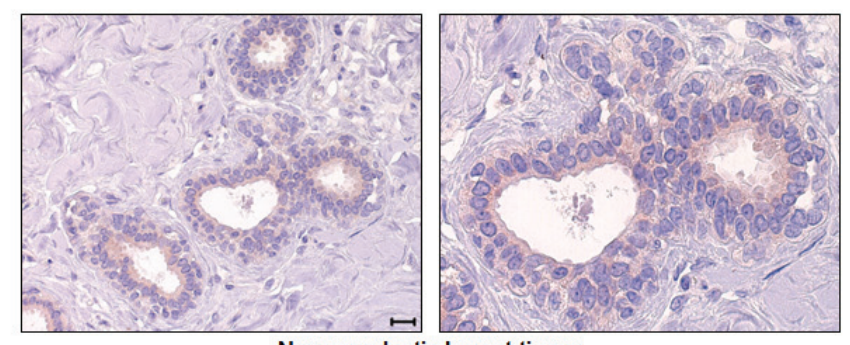

Non neoplastic breast tissue
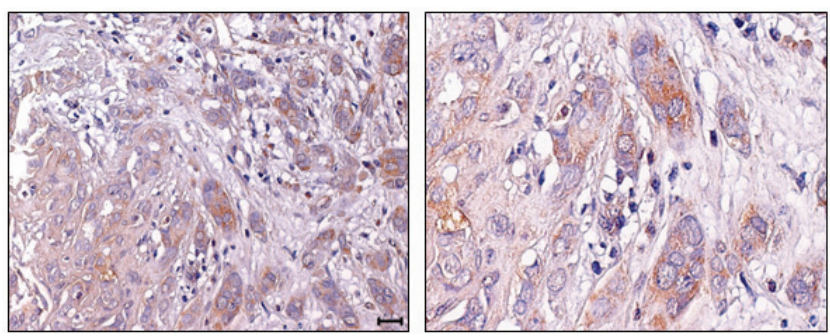

Primary breast cancer

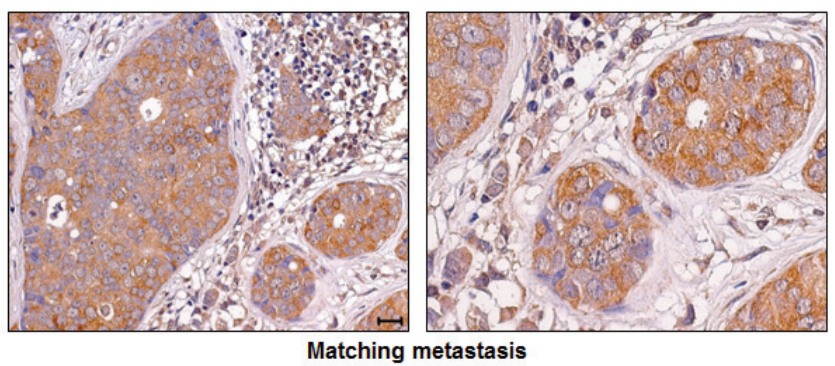

of PI3K-C2 $\beta$ in cell invasion and metastasis using the highly invasive breast cancer cell line MDA-MB-231. As shown in Figure 6A, 6B, stable PI3K-C2 $\beta$ downregulation indeed affected MDA-MB-231 cell invasion. The effect was primarily due to a defect in invasion, as counting of cells plated in parallel and incubated in $10 \%$ FBS for $48 \mathrm{~h}$ revealed only a slight reduction in cell number (Figure $6 C)$. Since it was previously reported that $\beta$ catenin plays a role in MDA-MB-231 cell migration [27] and our data indicated that both $\mathrm{PI} 3 \mathrm{~K}-\mathrm{C} 2 \beta$ and $\beta$ catenin regulate miR449a levels, we then investigated whether miR-449a was also involved in cell invasion. Transfection of sh scrambled MDA-MB-231 cells with mimic miR-449a significantly reduced cell invasion whereas a control miR had no effect (Figure 6D), indicating a role for the PI3K-C2 $\beta$-dependent regulation of miR-449a in invasion of MDA-MB-231 cells. To assess whether cell proliferation was also affected in the same experimental conditions, transfected cells were starved overnight, detached and counted (Figure 6E). Cells were then re-plated in growing media and counted after $48 \mathrm{~h}$ (i.e. the duration of the invasion assay, Figure $6 \mathrm{~F}$ ). These data showed that transfection of mimic miR-449a

B
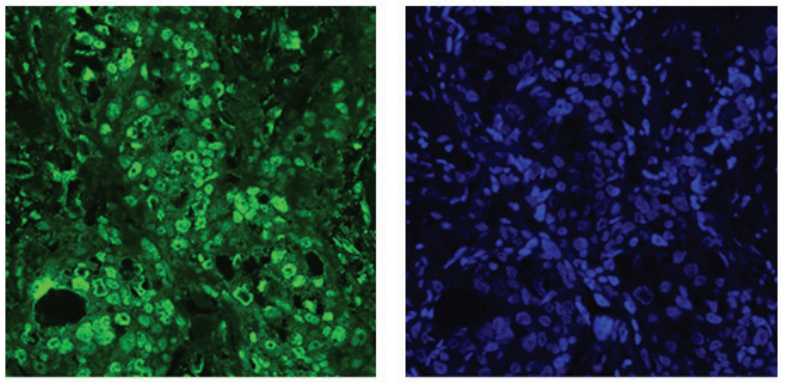

PI3K-C2 $\beta$

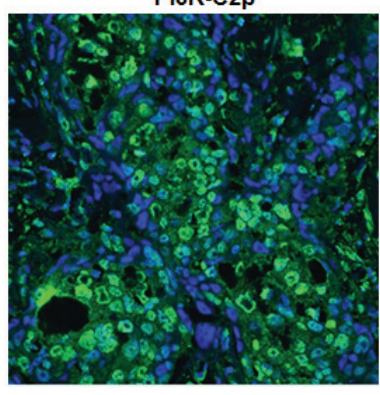

Merge

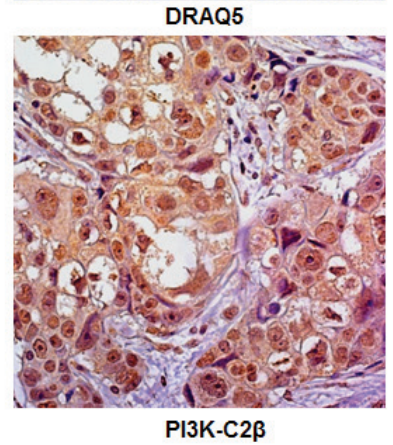

Figure 7: Expression of PI3K-C2 $\beta$ in breast tissues. A. Representative staining pattern of PI3K-C2 $\beta$ expression in TDLU from a non-neoplastic breast tissue, a primary breast cancer and matching metastasis. Panels on the right show magnifications of images presented in the corresponding left panels. Scale bars $=20 \mu \mathrm{m}$. B. Confocal microscopy images of PI3K-C2 $\beta$ (green signal), DRAQ5 (blue signal), and their merged signal in a breast cancer tissue. This case shows colocalization of PI3K-C2 $\beta$ expression with DRAQ5 nuclear dye. Bright field microscopy image of PI3K-C2 $\beta$ expression on the same case is also shown (original magnification 40x). 
Table 1: Spearman's correlation among the indicated markers assessed in primary breast tumors $(n=90)$

\begin{tabular}{|c|c|c|c|c|c|c|c|}
\hline & ER & PgR & Ki-67 & PI3K-C2 $\beta$ & \begin{tabular}{|l|} 
Cyclin \\
B1
\end{tabular} & $\beta$ catenin & \begin{tabular}{|l|} 
pSTAT33 \\
(Y705)
\end{tabular} \\
\hline $\begin{array}{l}\text { ER } \\
\text { Rho } \\
\text { P }\end{array}$ & 1 & $\begin{array}{l}0.545 \\
<0.001\end{array}$ & $\begin{array}{l}-0.121 \\
0.255\end{array}$ & $\begin{array}{l}0.042 \\
0.696\end{array}$ & $\begin{array}{l}-0.059 \\
0.581\end{array}$ & $\begin{array}{l}-0.003 \\
0.980\end{array}$ & $\begin{array}{l}0.127 \\
0.325\end{array}$ \\
\hline $\begin{array}{l}\text { PgR } \\
\text { Rho } \\
\text { P } \\
\end{array}$ & \begin{tabular}{|l|}
0.545 \\
$<0.001$ \\
\end{tabular} & 1 & \begin{tabular}{|l|l|}
-0.259 \\
0.014 \\
\end{tabular} & \begin{tabular}{|l}
-0.127 \\
0.234 \\
\end{tabular} & \begin{tabular}{|l|l}
-0.223 \\
0.036 \\
\end{tabular} & \begin{tabular}{|l|}
0.296 \\
0.007 \\
\end{tabular} & \begin{tabular}{|l|l}
0.008 \\
0.953 \\
\end{tabular} \\
\hline $\begin{array}{l}\text { Ki-67 } \\
\text { Rho } \\
\text { P } \\
\end{array}$ & \begin{tabular}{|l}
-0.121 \\
0.255 \\
\end{tabular} & \begin{tabular}{|l|}
-0.259 \\
0.014 \\
\end{tabular} & 1 & \begin{tabular}{|l|}
0.330 \\
0.002 \\
\end{tabular} & \begin{tabular}{|l|}
0.447 \\
$<0.001$ \\
\end{tabular} & \begin{tabular}{|l}
-0.111 \\
0.321 \\
\end{tabular} & \begin{tabular}{|l|l}
0.010 \\
0.941 \\
\end{tabular} \\
\hline $\begin{array}{l}\text { PI3K-C2 } \beta \\
\text { Rho } \\
\text { P }\end{array}$ & 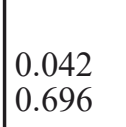 & $\begin{array}{l}-0.127 \\
0.234\end{array}$ & $\begin{array}{l}0.330 \\
0.002\end{array}$ & 1 & $\begin{array}{l}0.368 \\
<0.001\end{array}$ & $\begin{array}{l}-0.038 \\
0.735\end{array}$ & $\begin{array}{l}0.187 \\
0.146\end{array}$ \\
\hline $\begin{array}{l}\text { Cyclin B1 } \\
\text { Rho } \\
\text { P } \\
\end{array}$ & \begin{tabular}{|l}
-0.059 \\
0.581 \\
\end{tabular} & \begin{tabular}{|l}
-0.223 \\
0.036 \\
\end{tabular} & $\begin{array}{l}0.447 \\
<0.001 \\
\end{array}$ & $\begin{array}{l}0.368 \\
<0.001\end{array}$ & 1 & $\begin{array}{l}-0.076 \\
0.503\end{array}$ & $\begin{array}{l}0.023 \\
0.860 \\
\end{array}$ \\
\hline $\begin{array}{l}\beta \text { catenin } \\
\text { Rho } \\
\text { P } \\
\end{array}$ & \begin{tabular}{|l}
-0.003 \\
0.980 \\
\end{tabular} & \begin{tabular}{|l|}
$\mathbf{0 . 2 9 6}$ \\
$\mathbf{0 . 0 0 7}$ \\
\end{tabular} & \begin{tabular}{|l|}
-0.111 \\
0.321 \\
\end{tabular} & \begin{tabular}{|l}
-0.038 \\
0.735 \\
\end{tabular} & \begin{tabular}{|l}
-0.076 \\
0.503 \\
\end{tabular} & 1 & \begin{tabular}{|l|l}
0.266 \\
0.040 \\
\end{tabular} \\
\hline $\begin{array}{l}\text { pSTAT3 } \\
\text { (Y705) } \\
\text { Rho } \\
\text { P }\end{array}$ & $\begin{array}{l}0.127 \\
0.325\end{array}$ & $\begin{array}{l}0.008 \\
0.953\end{array}$ & $\begin{array}{l}0.010 \\
0.941\end{array}$ & $\begin{array}{l}0.187 \\
0.146\end{array}$ & $\begin{array}{l}0.023 \\
0.860\end{array}$ & \begin{tabular}{|l}
-0.266 \\
0.040
\end{tabular} & 1 \\
\hline
\end{tabular}

Rho $=$ Spearman's coefficient correlation. Significant correlations $(P<0.05)$ are indicated in bold.

reduced the number of cells (Figure 6E, 6F). However, the fact that downregulation of PI3K-C $2 \beta$ did not strongly affect cell number in the same experimental conditions (Figure 6C) possibly suggests additional roles for miR449a in MDA-MB-231 cells. On the other hand, we cannot exclude the possibility that the difference may be due to different amounts of miR-449a present in sh PI3K-C2 $\beta$ cells and in sh scrambled transiently transfected with the mimic miR-449a. Nevertheless, data indicate that both PI3K-C2 $\beta$ and miR-449a are involved in MDA-MB-231 cell invasion.

We then investigated the effect of PI3K-C2 $\beta$ downregulation in a lung metastasis model in vivo. Data indicated that survival of mice injected with sh PI3K-C2 $\beta$ MDA-MB-231 cells was significantly increased compared to mice injected with sh scrambled cells (Figure 6G, 6H). Specifically, we observed that only one mouse out of 8 mice injected with sh scrambled MDA-MB-231 cells was alive at day 59 after implant (Figure 6G). In contrast, almost all mice (7 out of 8) injected with MDA-MB-231 lacking PI3K-C2 $\beta$ were alive at day 59 after implant. The difference in survival between the two groups of mice was statistically significant $(p=0.0005$ ). These data suggest that PI3K-C $2 \beta$ has a key role in breast cancer metastasis formation.

To directly investigate the potential role of PI3K$\mathrm{C} 2 \beta$ in metastasis formation, mice injected with sh scrambled or sh PI3K-C2 $\beta$ MDA-MB-231 cells were sacrificed at the same time point to determine the number and size of lung metastases and to evaluate the tumor burden of metastasis, as described in the Methods. Images of the excised lungs are presented in Supplementary Figure S6A. First we observed that at the chosen time point only 2 out of 8 mice injected with sh PI3K-C2 $\beta$ MDA-MB-231 cells had developed lung metastases compared to 4 out of 7 mice injected with sh scrambled cells (Supplementary Table S2 and S3). Importantly, the number of metastases (Supplementary Figure S6B) and the metastasis burden (Supplementary Figure S6C) were clearly reduced in mice injected with cells lacking PI3K-C2 $\beta$, compared to mice injected with control cells. A detailed analysis of number/ size of metastases in each mouse and metastasis burden is presented in Supplementary Table S2 and S3.

These data indicate that PI $3 \mathrm{~K}-\mathrm{C} 2 \beta$ is required for breast cancer metastasis formation.

\section{Expression of PI3K-C2 $\beta$ in human breast tissues}

Once determined the key role of PI3K-C $2 \beta$ in breast cancer cells in vitro and in in vivo, we next investigated the expression of this enzyme in human non-neoplastic breast tissues, primary breast tumors and lymph-node metastases. Representative staining patterns of PI3K-C2 $\beta$ 
expression are shown in Figure 7. Whole sections of nonneoplastic breast tissues, stained with the anti PI3K-C2 $\beta$ antibody, revealed a very weak expression of the enzyme in the cytoplasm of luminal epithelia of terminal duct lobular units (TDLU) and of galactoforous ducts, but not in myoepithelia (Figure 7A). On the other hand, PI3K-C2 $\beta$ was clearly detectable in 45 out of $90(50.0 \%)$ primary breast cancer specimens (Figure 7A), with the proportion of tumor cells positive for cytoplasmic PI3K-C2 $\beta$ being in the range of 5 to $100 \%(49.3 \pm 5.0$, mean $\pm \mathrm{SE})$. A nuclear specific staining was also seen in a smaller cell proportion $(16.0 \pm 6.6$, mean $\pm \mathrm{SE})$. These cells also exhibited concomitant cytoplasmic expression of PI3K$\mathrm{C} 2 \beta$. Confocal microscopy analysis confirmed the nuclear localization of PI3K-C2 $\beta$ initially observed by bright field microscopy (Figure 7B). Spearman's correlation (Table 1) indicated that the expression of PI3K-C $2 \beta$ was directly correlated with the proliferative activity, as assessed by Ki-67 labeling index $(P=0.002)$, and with cyclin B1 expression $(P<0.001)$.

When PI3K-C2 $\beta$ expression was analyzed in twenty primary tumors/metastases pairs, we observed that the percentages of PI3K-C $2 \beta$ positive tumor cells in the synchronous lymph-node breast cancer metastases ranged from 71 to 100 , with a mean \pm SE of $90.0 \pm 1.6$, whereas the mean \pm SE percentage of cells positive for PI3K-C2 $\beta$ in the corresponding primary tumors was $47.9 \pm 9.0$. These data indicated that metastatic tumors contained statistically significantly higher numbers of PI3K-C2 $\beta$ positive cells $(P<0.001$ by independent samples $t$-test $)$.

Taken together these data indicate that PI3K-C2 $\beta$ is barely detectable in non-neoplastic breast tissues, whereas it is clearly expressed in breast primary tumors where it correlates with proliferative activity. Furthermore data indicate that PI3K-C2 $\beta$ is highly expressed in lymph-node breast cancer metastases.

PI3Ks have been firmly established as key players in the development and progression of many cancer types and indeed PI3K inhibitors have been developed and are currently being tested in clinical trials [4]. One of the limitations in our understanding of the contribution of $\mathrm{PI} 3 \mathrm{Ks}$ to cancer progression comes from the fact that the majority of the studies have been selectively focused on the involvement of one specific isoform, p110 $\alpha$, which is mutated in several cancer types [28]. The potential contribution of the other PI3K isoforms to cancer development and progression has been mostly disregarded. Only recently an increasing interest in understanding the role of the distinct PI3K isoforms has emerged [7, 29, 30]. Based on accumulating evidence suggesting that members of the class II subgroup of PI3Ks can have a role in cancer [7], here we investigated the potential role of the class II isoform PI3K-C2 $\beta$ in breast cancer. We detected accumulation of this specific isoform in breast cancer cell lines and human breast cancer specimens, suggesting a specific role for PI3K-C $2 \beta$ in this cancer type. A search in the cBio cancer genomics portal $[31,32]$ indicated that alteration of $P I K 3 C 2 B$ has been observed by sequencing and copy number analysis of breast cancer specimens. Specifically both amplification (Supplementary Figure S7A) and point mutations (Supplementary Figure S7A, S7B) have been detected. Importantly, KaplanMeier curves for invasive breast cancer cases indicated reduced survival in patients with $P I K 3 C 2 B$ alteration (Supplementary Figure S7C, S7D). These data support the conclusion that PI3K-C2 $\beta$ has a key role in breast cancer progression and metastasis. Nevertheless, to the best of our knowledge our study is the first to actually report an increased protein expression of PI3K-C2 $\beta$ in breast cancer cell lines, primary breast tumors and corresponding lymph-node metastases.

Our data show that $\mathrm{PI} 3 \mathrm{~K}-\mathrm{C} 2 \beta$ is required for breast cancer growth both in vitro and in vivo. In particular, data suggest that this enzyme may have a key role in proliferation induced by growth factors, such as estrogen and heregulin that are critical for breast cancer progression. Indeed the estrogen-induced in vivo tumor growth was inhibited upon orthotopic implantation of sh PI3K-C2 $\beta$ MCF7 compared to sh scrambled MCF7 cells. A trend towards inhibition of tumor growth was also observed upon implantation of sh PI3K-C2 $\beta$ MDA-MB-231 in the mammary fat pad, whereas no difference was observed when these cells were implanted subcutaneously, possibly suggesting a role for the microenvironment in PI3K$\mathrm{C} 2 \beta$-dependent tumor progression. Consistent with a role for PI3K-C2 $\beta$ in breast cancer growth, a significant correlation between PI3K-C2 $\beta$ and $\mathrm{Ki}-67$ proliferation index was observed in human breast cancer specimens.

In an effort to identify the mechanisms of the specific PI3K-C2 $\beta$-dependent regulation of cell growth, we observed that key signaling pathways were not altered in breast cancer cells upon specific downregulation of PI3K-C2 $\beta$. In particular, no difference in Akt activation was detected, consistent with our previous observations that class II PI3Ks activate distinct signaling pathways compared to the well-known class I PI3K/Akt pathway [7]. In contrast, we observed that downregulation of PI3K$\mathrm{C} 2 \beta$ reduced cyclin $\mathrm{B} 1$ protein expression. Interestingly, cyclin B1 expression is known to increase during the G2 phase of the cell cycle [33] when PI3K-C2 $\beta$ is most active [34] supporting the conclusion that PI3K-C2 $\beta$ is involved in regulation of cyclin $\mathrm{B} 1$ levels. On the other hand, it is worth mentioning that a previous study detected cyclin B1 in the G1 phase in cells from breast cancer tissues [35], which would be consistent with our observation that downregulation of $\mathrm{PI} 3 \mathrm{~K}-\mathrm{C} 2 \beta$ increases the percentage of cells in G1 phase following cellular synchronization. Importantly, cyclin B1 protein expression is upregulated in many breast cell lines and human mammary tumors [33]. Furthermore, cyclin B1 has been found to associate with poor prognosis and to be a predictor and classifier of outcomes in breast cancer [36, 37]. 
We further show that PI3K-C2 $\beta$-dependent regulation of cyclin $\mathrm{B} 1$ occurs through modulation of the specific microRNA miR-449a. Specifically, we demonstrate that downregulation of PI3K-C $2 \beta$ increases miR-449a levels. To the best of our knowledge this is the first demonstration of a role for a class II PI3K isoform in miR regulation. miR-449a belongs to the miR-34 family, which is expressed at a low level in several cancer cell lines and solid tumors including breast cancer [38]. More specifically, previous analysis of miRNA expression in 101 tumor samples from breast cancer patients indicated that miR-449a was downregulated in highly proliferative samples, with negative correlation with the cell cycle genes [38]. Downregulation of miR-449a in breast cancer was also confirmed by our analysis of publicly available databases. Reduced proliferation [36] and inhibition of the BrdU proliferation index [39] was observed in MCF7 transfected with miR-449a. In particular, these cells appeared to be completely arrested in G1 phase in the presence of nocodazole [39]. Consistent with these data, we observed that transfection of MCF7 cells with mimic miR-449a was able to induce G1 arrest, similarly to the effect observed upon downregulation of PI3K-C2 $\beta$.

The specific targets of miR-449 have only been partially identified and cyclin B1 is indeed among the validated miR-449 targets [25]. Consistent with this, our data demonstrate that counteracting the upregulation of miR-449a induced by PI3K-C2 $\beta$ downregulation, using specific anti miR-449a increases cyclin B1 protein levels.

Our data further identified one of the mechanisms by which PI3K-C2 $\beta$ can potentially regulate the levels of miR-449a. Specifically, we observed that downregulation of PI3K-C $2 \beta$ was associated with reduced activation of $\beta$ catenin in MDA-MB-231 cells and that downregulation of $\beta$ catenin resulted in increased miR-449a levels. These data suggest that PI3K-C2 $\beta$ may regulate miR-449a in a mechanism involving $\beta$ catenin activation in MDAMB-231 cells. An interesting possibility is that PI3K-C2 $\beta$ may specifically regulate the cancer stem cell fraction where Wnt signaling plays a major role and therefore the observed effect of $\beta$ catenin/LEF1 in MDA-MB-231 cells may be due to a reduction in stem cells number. There is evidence that indicates an involvement of $\beta$ catenin in miRNA repression $[40,41]$, even though the mechanism by which $\beta$ catenin downregulates miR-449a in breast cancer is currently unknown. Importantly, it has been reported that $\beta$ catenin plays a critical role in breast cancer development and tumorigenesis [42] and it can be a prognostic marker for breast cancer [43]. On the other hand, our data indicate that downregulation of $\beta$ catenin was not able to increase the percentage of MCF7 cells in G1 phase of the cell cycle, as observed upon downregulation of PI3K-C2 $\beta$ or transfection with the mimic miR-449a. This is consistent with a previous study indicating that inhibition of $\beta$ catenin/cAMP-responsive element-binding protein-binding protein-mediated transcription, inhibited cell proliferation in MDA-MB-231 but not in MCF7 cells [24]. These results suggest the existence of additional, $\beta$ catenin-independent mechanisms by which PI3K-C2 $\beta$ modulates miR-449a levels in MCF7 cells. Since we observed that PI3K-C2 $\beta$ regulates activation of the transcription factor STAT3, which in turn can also be involved in miR-34 family regulation [44], we then tested whether STAT3 could be involved in PI3K-C2 $\beta$-dependent regulation of miR-449a in MCF7 cells. However, the observation that downregulation of STAT3 did not affect cell cycle progression supports the conclusion that STAT3 is not involved in the regulation of miR-449a in MCF7 cells. While we cannot completely rule out the possibility that downregulation of either $\beta$ catenin or STAT3 could possibly modulate miR-449a levels in MCF7 cells in different experimental conditions, overall these data suggest that PI3K-C $2 \beta$ modulates miR449a levels in MCF7 cells through additional mechanisms of regulation. In this respect, it has been reported that miR449a levels can be epigenetically repressed by histone H3 Lys27 trimethylation in MCF7 cells [39]. Furthermore, MCF7 ChIP-seq data from the ENCODE project revealed the presence of a H3K27me3 peak upstream miR-449a, whereas no activating histone modifications were detected (data not shown).

It has been further shown that miR-449a is able to inhibit migration and invasion and indeed a recent study reported that low expression of miR-449a was correlated with lymph-node metastasis [45]. These data indicated that miR-449 is a potential tumor suppressor that regulates cell cycle, invasion and metastasis by targeting multiple oncogenes. Consistent with this, we observed that downregulation of PI3K-C2 $\beta$, as well as transfection of cells with mimic miR-449a, inhibited invasion of MDAMB-231 cells. More importantly, we observed that survival of mice injected with sh PI3K-C2 $\beta$ MDA-MB-231 was significantly increased compared to mice injected with sh scrambled cells in an in vivo model of lung metastasis. Additional experiments revealed a reduced number of metastasis and reduced metastasis burden in mice injected with cells lacking PI3K-C2 $\beta$ compared to mice injected with control cells. These data strongly supported the conclusion that PI3K-C $2 \beta$ has a key role in metastasis formation induced by highly invasive breast cancer cells. Indeed, further analysis of the expression levels of $\mathrm{PI} 3 \mathrm{~K}-\mathrm{C} 2 \beta$ in twenty primary tumors-metastasis pairs by immunohistochemistry analysis revealed that PI3K-C2 $\beta$ expression was significantly increased in lymph-node metastasis compared to matching primary tumors.

In summary, in this study we reported that PI3K$\mathrm{C} 2 \beta$ is overexpressed in breast cancer cell lines and in human breast tumors and it has a critical role in the regulation of breast cancer cell growth. We demonstrated that downregulation of PI3K-C2 $\beta$ inhibits breast cancer cell invasion in vitro and breast cancer metastasis in vivo. Increased levels of PI3K-C $2 \beta$ were also detected 
in lymph-nodes metastasis compared to primary tumors. Data further indicated that $\mathrm{PI} 3 \mathrm{~K}-\mathrm{C} 2 \beta$ regulates cyclin B1 expression through modulation of miR-449a. In addition, we showed that this novel PI3K-C2 $\beta /$ miR-449a pathway can also play a key role in the regulation of cell invasion. These data demonstrate that PI3K-C2 $\beta$ plays a pivotal role in breast cancer progression as well as in metastasis formation, and provide a strong rationale for the development of compounds that inhibit this PI3K isoform as novel potential therapeutic strategies.

\section{MATERIALS AND METHODS}

\section{Chemicals and reagents}

Human heregulin B1 (HER) and human insulin like growth factor-1 (IGF-1) were obtained from Peprotec EC Ltd. (London, UK). Human insulin (INS), human 17 $\beta$-Oestradiol $\left(\mathrm{E}_{2}\right)$, Protease inhibitor cocktail, Phosphatase inhibitor cocktail A and Phosphatase inhibitor cocktail B were from Sigma-Aldrich (Gillingham, UK). BCA Protein Assay kit was from Thermo Scientific Pierce (Thermo Fisher Scientific, Inc, Rockford, IL, USA). Anti PI3K-C2 $\beta$, anti PI3K-C2 $\alpha$ and mouse anti cyclin B1 antibodies were from BD Biosciences (Oxford, UK). Rabbit anti cyclin B1, anti cyclin D1, anti cyclin D2, rabbit anti phospho Thr202/Tyr204 ERK1/2, anti phospho Ser473 Akt, anti phospho Ser2448 mTOR, anti phospho Thr389 S6K, anti phospho Ser241 PDK1, anti phospho Ser9 GSK3 $\beta$, anti phospho Tyr705 Stat3, anti phospho Ser727 STAT3, anti GSK3 $\beta$, anti PDK1, anti S6K, anti mTOR, anti $\mathrm{p} 110 \alpha$, anti $\mathrm{p} 110 \beta$, anti $\beta$ catenin were from Cell Signaling Technology, Inc. (Danvers, MA, USA). Anti Akt, mouse anti phospho Thr202/Tyr204 ERK1/2, anti ERK2, anti actin, anti $\beta$ tubulin, anti LEF-1 were from Santa Cruz Biotechnology, Inc. (Dallas, Texas, USA). Anti active $\beta$ catenin (that recognises active form of $\beta$ catenin, dephosphorylated on Ser37 or Thr41) was from Merck Millipore (Billerica, MA, USA). Anti GAPDH was from Abcam (Cambdrige, UK). Anti DRAQ5 was from BioStatus (Shepshed, Leicestershire, UK). Horseradish peroxidase-conjugated secondary anti-mouse, anti-rabbit and anti-goat antibodies were from DAKO UK Ltd. (Ely, UK) or from Sigma Aldrich (Gillingham, UK). Enhanced chemiluminescence reagent (ECL) was from GE Healthcare (Little Chalfont, UK) or Merck Millipore. Non targeting siRNA ("si scrambled") was from Ambion ${ }^{\circledR}$ (Life Technologies, Paisley, UK). siRNA targeting PI3K-C2 $\beta$ (sequence 1) was from Qiagen (Limburg, Netherlands), all other siRNAs were from Dharmacon, Inc. (GE Healthcare). Anti miR control and anti-miR-449a were from Life Technologies. Unless otherwise stated all other reagents were obtained from Sigma-Aldrich.

\section{Cell culture and transfection}

The BRE80 cell line was a kind gift from Dr. Maria Konstantoulakis (University College London, UK). All other cell lines were obtained from American Type Culture Collection (ATCC Middlesex, UK). MCF10A and BRE80 cell lines were cultured in $\mathrm{MEBM}^{\circledR}$ phenol red free media, supplemented with MEGM ${ }^{\circledR}$ SingleQuots ${ }^{\circledR}$ (Lonza, Walkersville MD). HBL-100, MDA-MB-231, MDAMB-468, SKBR-3, MCF7 and T47D cell lines were all cultured in DMEM media supplemented with $10 \% \mathrm{FBS}$, penicillin/ streptomycin, and L-glutamine, all from Life Technologies. All cell lines were maintained at $37^{\circ} \mathrm{C}$ in a humidified atmosphere of $95 \%$ air and $5 \% \mathrm{CO}_{2}$. siRNAs and anti miRs were transfected using Oligofectamine ${ }^{\mathrm{TM}}$ (Life Technologies) or HiPerFect ${ }^{\circledR}$ (Qiagen), according to the manufacturer's instructions.

\section{Generation of stable cell lines}

Specific shRNA targeting PI3K-C2 $\beta$ was designed based on a previously validated sequence [16] and subcloned into pSuperior vector (Oligogene, Seattle, WA, USA). A recombinant pSuperior containing a control (scrambled) shRNA was also generated. MCF7 were transfected using the AMAXA nucleofector electroporation system (Lonza, Walkersville, MD, USA), following the manufacturer's standard operating instructions. T47D were transfected using Lipofectamine ${ }^{\circledR}$ (Life Technologies) according to the manufacturer's instructions. Stable MDA-MB-231 cells were generated by retroviral infection, as previously described [46]. Single clones (MCF7) and cell populations (T47D, MDAMB-231) were selected and maintained in standard media with $1 \mu \mathrm{g} / \mathrm{ml}$ (MCF7, MDA-MB-231) or $0.5 \mu \mathrm{g} / \mathrm{ml}$ (T47D) puromycin.

\section{Cell growth assays}

For cell counting assays, cells were plated into six well Nunc multiwell plates at a density of $2 \times 10^{5} /$ well for MCF7 cells and at $5 \times 10^{5} /$ well for T47D. After $24 \mathrm{~h}$ cells were incubated in DMEM/F12-phenol red-free and serum -free media supplemented with penicillin/ streptomycin, and L-glutamine for further $24 \mathrm{~h}$ before incubation in phenol red-free and serum-free media containing $10 \mathrm{nM}$ $\mathrm{E}_{2}$ or $50 \mathrm{ng} / \mathrm{ml} \mathrm{HER}$.

For anchorage-independent growth, a mix of $0.6 \%$ agarose in DMEM supplemented with $10 \%$ FBS was allowed to polymerize in a 6 well plate for $30 \mathrm{~min}$. MCF7 or T47D cells were then resuspended in a mix of $0.3 \%$ agarose in DMEM supplemented with $10 \%$ FBS and plated on the 6 well plate. DMEM containing $10 \%$ FBS was added on top of the second agarose layer and replaced 
once a week. After 3 weeks, the 6 well plate was incubated with $0.0005 \%$ crystal violet in methanol overnight and the number of colonies was assessed by cell counting.

\section{Cell cycle analysis}

MCF7 cells were synchronized by incubation for $24 \mathrm{~h}$ in media deprived of serum and phenol red followed by $24 \mathrm{~h}$ or $48 \mathrm{~h}$ incubation in growing media. After washing with PBS, cells were detached, collected and centrifuged at 1,200 rpm for 5 minutes. Pelleted cells were fixed in icecold $70 \%$ ethanol and re-suspended in $500 \mu \mathrm{l}$ Vindellövs Propidium Iodide solution $(50 \mathrm{mg} / \mathrm{ml})$. Cells were then analyzed by flow cytometry collecting 20,000 events per sample using Fluorescence activated cell sorting (FACS) Diva software.

\section{Western blotting analysis of signaling molecules}

Activation of signaling molecules was analyzed either in cells kept in serum or upon cellular stimulation. Where indicated cells were serum deprived for $24 \mathrm{~h}$ in DMEM/F12-phenol red free (Life Technologies), supplemented with penicillin/ streptomycin, and L-glutamine. Cells were washed with HEPES-buffered incubation medium (HBM: NaCl $140 \mathrm{mM}$, KCl $5 \mathrm{mM}$, $\mathrm{NaHCO}_{3} 5 \mathrm{mM}, \mathrm{MgCl}_{2}, 1.1 \mathrm{mM}, \mathrm{Na}_{2} \mathrm{HPO}_{4} 1.2 \mathrm{mM}, \mathrm{CaCl}_{2}$ $1.2 \mathrm{mM}$, glucose $5.5 \mathrm{mM}$ and HEPES $20 \mathrm{mM}$, pH 7.4) and incubated for $10 \mathrm{~min}$ with fresh HBM containing $10 \mu \mathrm{g} / \mathrm{ml}$ INS, 50ng/ml HER, 10ng/ml IGF-1 or $10 \mathrm{nM} \mathrm{E}_{2}$. HBM was removed, and plates quickly washed with icecold PBS, pH $7.4\left(\mathrm{Ca}^{2+}\right.$-free supplemented with $200 \mu \mathrm{M}$ EGTA) on ice. The cell monolayer was rapidly scraped and collected in ice-cold lysis buffer [50 mM Tris, $\mathrm{pH}$ 7.5, $150 \mathrm{mM} \mathrm{NaCl}, 1 \%$ Triton X-100, 2 mM EDTA, 2 $\mathrm{mM}$ EGTA, $1 \mu \mathrm{l} / \mathrm{ml}$ Protease inhibitor cocktail, $1 \mu \mathrm{l} / \mathrm{ml}$ Phosphatase inhibitor cocktail A and $1 \mu \mathrm{l} / \mathrm{ml}$ Phosphatase inhibitor cocktail B] and left for $45 \mathrm{~min}$. Samples were then centrifuged at $1000 \times g$ for $5 \mathrm{~min}$ at $+4^{\circ} \mathrm{C}$ to remove cell debris. The supernatant (crude homogenate) was kept, and protein concentration was determined by Bradford assay. Alternatively cells were lysed using 2\% SDS in PBS. Samples were then boiled at $100^{\circ} \mathrm{C}$ for $5 \mathrm{~min}$ in SDS sample buffer $[62.5 \mathrm{mM}$ Tris, $2 \%$ SDS, $10 \%$ glycerol, $5 \% \beta$-mercaptoethanol and $0.002 \%$ bromophenol blue]. Samples were separated by SDS-PAGE and transferred on nitrocellulose membranes by electroblotting. Membranes were then incubated in TBS (20 mM Tris, $\mathrm{pH} 7.5,150$ $\mathrm{mM} \mathrm{NaCl}$ ) or PBS supplemented with $0.1 \%$ (v/v) Tween 20 (TBS-T, PBS-T) and containing 5\% skimmed milk powder for $1 \mathrm{~h}$ at room temperature, followed by overnight incubation with primary antibodies at $+4^{\circ} \mathrm{C}$. After washing with TBS-T or PBS-T membranes were incubated with secondary antibodies for $1 \mathrm{~h}$, washed with TBS-T or PBS-T and exposed to ECL reagent. When indicated membranes were stripped by washing twice for $10 \mathrm{~min}$ in TBST followed by two 30 min washes in glycine-based stripping buffer (1.5\% glycine, $0.1 \%$ SDS, $1 \%$ Tween $20 \mathrm{pH}$ 2.2). Alternatively membranes were stripped by incubation for $30 \mathrm{~min}$ at $50^{\circ} \mathrm{C}$ in SDS-based stripping buffer $(62.5 \mathrm{mM}$ Tris $\mathrm{HCl} \mathrm{pH} 6.8,0.5 \%$ SDS, $0.7 \% \beta$ mercapthoethanol).

\section{Human phosphokinase array}

Analysis of the phosphorylation status of several kinases and proteins was performed using Proteome Profiler Human Phospho-Kinase Array Kit (Cat. No. ARY003, R\&D Systems, Abingdon, UK) according to the manufacturer's instructions. Briefly, stable MDAMB-231 cell lines kept in serum were washed in PBS and incubated with Lysis Buffer 6 for $30 \mathrm{~min}$ at $+4^{\circ} \mathrm{C}$. Cell debris were removed by centrifugation at $14,000 \mathrm{x}$ $\mathrm{g}$ for 5 minutes and protein concentration was assessed by BCA Protein Assay. After blocking in Array Buffer 1 for $1 \mathrm{~h}$ at room temperature each membrane was incubated with $600 \mu \mathrm{g}$ of cell lysate overnight at $+4^{\circ} \mathrm{C}$. Membranes were then washed with $1 \mathrm{X}$ Wash Buffer and incubated with diluted Detection Antibody Cocktail A and B for $2 \mathrm{~h}$ at room temperature followed by incubation with Streptavidin-HRP for additional $30 \mathrm{~min}$. Membranes were then incubated with Chemi Reagent Mix and exposed on an X-ray film for 1-10 minutes. Densitometry analysis was performed using Image $\mathrm{J}$ software according to the manufacturer's instructions.

\section{Invasion assay}

Assay was performed in MDA-MB-231 stable cell lines as previously described [47].

\section{miRs analysis}

To assess miRs levels cells were washed twice with PBS and lysed using QIAzol Lysis Reagent (Qiagen). Total RNA was extracted using miRNAse Mini Kit (Qiagen) and cDNA synthesised using TaqMan ${ }^{\circledR}$ MicroRNA Reverse Transcription kit (Life Technologies) according to manufacturer's instructions. PCR was performed according to manufacturer's instructions (TaqMan ${ }^{\circledR}$ MicroRNA Assays Protocol, Life Technologies). Analysis of miRs expression was performed using the cycle threshold (Ct) and RNU48 as endogenous control. Levels of miRs were obtained using the $\Delta \Delta \mathrm{Ct}$ method and expressed as $2^{(-\Delta \Delta C t)}$ values. All experiments were performed in triplicate. 


\section{Immunohistochemistry}

Tissue microarrays (TMA) were constructed by extracting 2-mm diameter cores of histologically confirmed invasive breast carcinoma areas from 90 invasive primary breast tumors, and matching lymph-node metastases ( $n=20$ pairs), as previously described [48]. TMA sections were stained using the monoclonal mouse anti-human PI3K-C2 $\beta$ at 1:500 dilution for $30 \mathrm{~min}$ after antigen retrieval performed by two microwave treatments at $750 \mathrm{~W}$ and $160 \mathrm{~W}$ for $10 \mathrm{~min}$ each in $1 \mathrm{M}$ urea buffer (pH 8.0). Whole sections of non-neoplastic breast tissues from 10 patients were also stained. EnVision kit (Dako, Glostrup, Denmark) was used for signal amplification. After antigen retrieval by thermostatic bath at $96^{\circ} \mathrm{C}$ in 10 $\mathrm{mM}$ citrate buffer, $\mathrm{pH} 6.0$ for $40 \mathrm{~min}$ sections were also incubated with anti-EstogenReceptor- $\alpha$ (ER) MoAb 6F11 (Menarini, Florence, Italy), anti-Progesteron Receptor (PgR) MoAb 1A6 (Menarini), and anti-Ki-67 MoAb MIB1 (Dako) for $30 \mathrm{~min}$ at room temperature. For $\beta$-catenin (clone $14 / \beta$-catenin, BD Transduction Laboratories, San Jose, CA) epitope retrieval was done by microwave heated citrate buffer (pH 6.0), and in $1 \mathrm{mmol} / \mathrm{L}$ EDTA ( $\mathrm{pH} 8.0$ ) for pospho-Stat3 (Tyr705) (clone 3E2, Cell Signaling, Danvers, MA). The immunoreactions were revealed by a streptavidin-biotin-enhanced peroxidase system (Super Sensitive Link-Label IHC DetectionSystem; BioGenex, Space, Milan, Italy). For cyclin B1, staining was performed using a rabbit monoclonal anti-human antibody (clone Y106, Epitomics, Cambridge, UK), at 1:200 dilution for $30 \mathrm{~min}$, after antigen retrieval performed by microwave treatment for $25 \mathrm{~min}$ in Tris-EDTA buffer (pH 9.0). An anti-rabbit EnVision kit (Dako) was used for signal amplification. Positive and negative controls were included for each antibody and in each batch of staining. Correlation between PI3K-C2 $\beta$ expression and ER, PgR, Ki-67, cyclin B1, $\beta$-catenin and pospho-Stat3 (Tyr705) expressions was assessed by Spearman's rho correlation. The independent samples $t$-test was used to compare the PI3K-C2 $\beta$ expression in primary tumors and matched lymph-node metastasis. The SPSS (version 15.0) statistical program (SPSS Inc., Chicago, IL) was used for analyses. All $\mathrm{P}$ values are two-sided; $p<0.05$ was considered as statistically significant.

For confocal laser-scanning microscopy (LSM 510 META microscope, Zeiss, Jena, Germany), after antigen retrieval, sections were incubated with the mouse monoclonal antibody anti PI3K-C2 $\beta$. Then, Alexa Fluor 488 conjugated rabbit anti-mouse $\mathrm{IgG}$ (Molecular Probes, Eugene, OR) was used (60 min incubation at 1:200 dilution) for signal detection. Cell nuclei were counterstained with DRAQ5 (BioStatus, Shepshed, Leicestershire, UK).

\section{In vivo experiments}

Nude immunodeficient mice were obtained from Charles River, UK or Harlan-Italy and maintained under specific pathogen-free conditions with food and water provided ad libitum. All animals in this study were housed and sacrificed in accordance with Home Office Guidelines and under a project license. Procedures involving animals and their care were conducted in conformity with institutional guidelines that are in compliance with national (Legislative Decree 116 of January 27, 1992, Authorization n.169/94-A issued December 19, 1994, by Ministry of Health) and international laws and policies (EEC Council Directive 86/609, OJL 358. 1, December 12, 1987; Standards for the Care and Use of Laboratory Animals, United States National Research Council, Statement of Compliance A5023-01, November 6, 1998). Where required, mice were humanely sacrificed via a rising concentration of $\mathrm{CO}_{2}$ to near $100 \%$ followed by cervical dislocation.

For MCF7 orthotopic experiments cells were diluted in $200 \mu 1$ growth medium $+200 \mu 1 \mathrm{BD}$ Matrigel ${ }^{\mathrm{TM}}$ (BD Biosciences). The cell suspension was injected into the mammary fat pad of 5 week-old pathogen-free nude mice on day $0 . \mathrm{E}_{2}$ pellets $(1.7 \mathrm{mg} /$ pellets, IRA, Sarasota, FL) were injected subcutaneously into the neck with pellet trochar (IRA). At the end of the experiment tumors volume was measured with caliper according to the formula length $\mathrm{x}$ width $\mathrm{x}$ height.

For experiments with MDA-MB-231 a total of $7 \times 10^{6}$ exponentially growing cells were injected subcutaneously into the left flank of female 4-week-old athymic nude (nu/nu) mice. Eight mice/group were used in these experiments. For orthotopic tumor growth, mice were anesthetized with a continuous flow of $3 \%$ isoflurane/ oxygen mixture. Then, a $1-\mathrm{cm}$ incision in the skin closed to the mammary fat pad was performed to expose it, and $10^{5}$ cells in a total volume of $10 \mu 1$ of PBS were injected into the mammary gland using an Hamilton ${ }^{\circledR}$ syringe equipped with a 26-gauge needle. By exposing the fat pad, we were able to ensure that the cells were injected into the tissue and not into the s.c. space. Tumor diameters were measured with a caliper twice weekly until the animals were sacrificed. Tumor weight was derived from tumor volume (assuming a density of 1) by the formula: (length $\mathrm{x}$ width2)/2. Body weights were measured weekly.

To monitor survival in the lung metastasis in vivo experiment, $5 \times 10^{5}$ cells were injected i.v. and the animals were monitored daily and body weights recorded. At symptoms of distress and body weight loss the animals were sacrificed and lungs excised. Survival of the animals was calculated from the day of cancer cells injection (day 0 ) to the day of sacrifice.

To monitor lung metastasis formation, $5 \times 10^{5}$ cells were injected i.v. as above and mice were sacrificed the day after the first mouse from group injected with sh 
scrambled MDA-MB-231 cells died. Lungs were then excised and fixed in Bouin's solution (Bio-Optica). Superficial metastatic nodules were counted and measured using a dissecting microscope. Specifically number of colonies per lung and the diameter of colonies were recorded. Metastasis volume was calculated as diameter ${ }^{3}\left(\mathrm{~mm}^{3}\right) / 2$, and the lung tumor burden was derived from the sum of the volumes of all counted colonies, as previously reported [49].

\section{miRs array}

miRs array was performed at the Genome Centre, Queen Mary University of London.

\section{miRs search}

MetaCore $^{\mathrm{TM}}$ version 6.10 (GeneGo Inc) was used to identify miRs that were likely to target cyclin B1.

\section{Public datasets analysis}

Two independent microarray datasets, publicly available on Array Express (E-GEOD-19783 and E-GEOD-12848), were analyzed for miR expression across 101 and 18 primary human breast cancer samples, respectively. Samples were stratified according to the grade, molecular tumor subtype (Lum A, Lum B, ERBB2+, Basal-like, Normal-like), Estrogen Receptor status, HER2 status, TP53 status, tumor size, cancer staging. For the E-GEOD-19783 dataset, raw data were available and the quantile algorithm was used for data normalization. For the E-GEOD-12848 dataset, the gTotalGeneSignal from GeneView files was used to analyze samples. Student $T$-test p-value and log base 2 fold change were calculated for each class comparison.

\section{TF binding site analysis}

Match tool from TRANSFAC [50] was used for identification of transcription factors with putative binding sites within $10 \mathrm{~K}$ bases upstream the miR-449a TSS. The weight matrix search was performed using a cut-off that minimizes the sum of both false positive and negative error rates.

\section{Cellular senescence assay}

Cell senescence was assessed using the senescence $\beta$-galactosidase staining kit from Cell Signaling Technology, Inc. according to the manufacturer's instructions.

\section{ACKNOWLEDGMENTS}

RF is supported by Pancreatic Cancer Research Fund (grant to MF). MF and TM are supported by Prostate Cancer UK (PG12-23 and PG13-029). MB is supported by Associazione Italiana Ricerca Cancro (IG-12915). GC is supported by Compagnia di San Paolo. PO is supported by Lauretana SpA (Biella, Italy).

\section{Authors' contributions}

Designed and performed the in vitro experiments: A.Chikh, R. Ferro, J.J.Abbott, R.Piñeiro, R. Buus, T. Maffucci, M. Falasca

Designed and performed the in vivo experiments: M.Iezzi, F. Ricci

Designed and supervised the in vivo experiments:

M.Broggini, M.Piantelli, M.Falasca

Performed immunohistochemistry analysis: R.Lattanzio, M. Piantelli

Performed miRs analysis: P. Ostano, G. Chiorino

Analyzed the data: A.Chikh, R. Ferro, J.J. Abbott, R.Piñeiro, M. Iezzi, F. Ricci, D.Bergamaschi, P.Ostano, G.Chiorino, R.Lattanzio, M.Broggini, M.Piantelli, T.Maffucci, M.Falasca

Contributed to manuscript writing: A.Chikh, R.Ferro, J.J.Abbott, D.Bergamaschi, G.Chiorino, R.Lattanzio, M.Broggini, M.Piantelli

Wrote the manuscript: T.Maffucci, M.Falasca

Conceived, planned, led and supervised the whole study: M.Falasca

\section{CONFLICTS OF INTEREST}

The authors declare that they have no conflict of interest.

\section{Editorial note}

This paper has been accepted based in part on peerreview conducted by another journal and the authors' response and revisions as well as expedited peer-review in Oncotarget.

\section{REFERENCES}

1. Higgins MJ and Baselga J. Targeted therapies for breast cancer. The Journal of clinical investigation. 2011; 121:3797-3803.

2. Yuan TL and Cantley LC. PI3K pathway alterations in cancer: variations on a theme. Oncogene. 2008; 27:54975510 .

3. Wong KK, Engelman JA and Cantley LC. Targeting the PI3K signaling pathway in cancer. Current opinion in 
genetics \& development. 2010; 20:87-90.

4. Falasca M. PI3K/Akt signalling pathway specific inhibitors: a novel strategy to sensitize cancer cells to anti-cancer drugs. Current pharmaceutical design. 2010; 16:1410-1416.

5. Vanhaesebroeck B, Guillermet-Guibert J, Graupera M and Bilanges B. The emerging mechanisms of isoform-specific PI3K signalling. Nature reviews Molecular cell biology. 2010; 11:329-341.

6. Miller TW, Rexer BN, Garrett JT and Arteaga CL. Mutations in the phosphatidylinositol 3-kinase pathway: role in tumor progression and therapeutic implications in breast cancer. Breast cancer research. 2011; 13:224.

7. Falasca $M$ and Maffucci T. Regulation and cellular functions of class II phosphoinositide 3-kinases. The Biochemical journal. 2012; 443:587-601.

8. Chiaretti S, Li X, Gentleman R, Vitale A, Wang KS, Mandelli F, Foa R and Ritz J. Gene expression profiles of B-lineage adult acute lymphocytic leukemia reveal genetic patterns that identify lineage derivation and distinct mechanisms of transformation. Clinical cancer research. $2005 ; 11: 7209-7219$

9. Qian Z, Fernald AA, Godley LA, Larson RA and Le Beau MM. Expression profiling of CD34+ hematopoietic stem/ progenitor cells reveals distinct subtypes of therapy-related acute myeloid leukemia. Proceedings of the National Academy of Sciences of the United States of America. 2002; 99:14925-14930.

10. Knobbe $\mathrm{CB}$ and Reifenberger G. Genetic alterations and aberrant expression of genes related to the phosphatidylinositol-3'-kinase/protein kinase B (Akt) signal transduction pathway in glioblastomas. Brain pathology. 2003; 13:507518.

11. Boller D, Doepfner KT, De Laurentiis A, Guerreiro AS, Marinov M, Shalaby T, Depledge P, Robson A, Saghir N, Hayakawa M, Kaizawa H, Koizumi T, Ohishi T, Fattet S, Delattre O, Schweri-Olac A, et al. Targeting PI3KC2beta impairs proliferation and survival in acute leukemia, brain tumours and neuroendocrine tumours. Anticancer research. 2012; 32:3015-3027.

12. Arcaro A, Khanzada UK, Vanhaesebroeck B, Tetley TD, Waterfield MD and Seckl MJ. Two distinct phosphoinositide 3-kinases mediate polypeptide growth factor-stimulated PKB activation. The EMBO journal. 2002; 21:5097-5108.

13. Russo A and O'Bryan JP. Intersectin 1 is required for neuroblastoma tumorigenesis. Oncogene. 2012; 31:48284834 .

14. Koutros S, Schumacher FR, Hayes RB, Ma J, Huang WY, Albanes D, Canzian F, Chanock SJ, Crawford ED, Diver WR, Feigelson HS, Giovanucci E, Haiman CA, Henderson BE, Hunter DJ, Kaaks R, et al. Pooled analysis of phosphatidylinositol 3-kinase pathway variants and risk of prostate cancer. Cancer research. 2010; 70:2389-2396.

15. Liu P, Morrison C, Wang L, Xiong D, Vedell P, Cui P, Hua
X, Ding F, Lu Y, James M, Ebben JD, Xu H, Adjei AA, Head K, Andrae JW, Tschannen MR, et al. Identification of somatic mutations in non-small cell lung carcinomas using whole-exome sequencing. Carcinogenesis. 2012; 33:12701276.

16. Maffucci T, Cooke FT, Foster FM, Traer CJ, Fry MJ and Falasca M. Class II phosphoinositide 3-kinase defines a novel signaling pathway in cell migration. The Journal of cell biology. 2005; 169:789-799.

17. Katso RM, Pardo OE, Palamidessi A, Franz CM, Marinov M, De Laurentiis A, Downward J, Scita G, Ridley AJ, Waterfield MD and Arcaro A. Phosphoinositide 3-Kinase C2beta regulates cytoskeletal organization and cell migration via Rac-dependent mechanisms. Molecular biology of the cell. 2006; 17:3729-3744.

18. Russo A, Okur MN, Bosland $\mathrm{M}$ and O'Bryan JP. Phosphatidylinositol 3-kinase, class 2 beta (PI3KC2beta) isoform contributes to neuroblastoma tumorigenesis. Cancer letters. 2015; 359:262-268.

19. Arcaro A, Zvelebil MJ, Wallasch C, Ullrich A, Waterfield MD and Domin J. Class II phosphoinositide 3-kinases are downstream targets of activated polypeptide growth factor receptors. Molecular and cellular biology. 2000; 20:38173830 .

20. Bouhallier F, Allioli N, Lavial F, Chalmel F, Perrard MH, Durand P, Samarut J, Pain B and Rouault JP. Role of miR$34 \mathrm{c}$ microRNA in the late steps of spermatogenesis. Rna. 2010; 16:720-731.

21. Marcet B, Chevalier B, Luxardi G, Coraux C, Zaragosi LE, Cibois M, Robbe-Sermesant K, Jolly T, Cardinaud B, Moreilhon C, Giovannini-Chami L, Nawrocki-Raby B, Birembaut P, Waldmann R, Kodjabachian L and Barbry P. Control of vertebrate multiciliogenesis by miR-449 through direct repression of the Delta/Notch pathway. Nature cell biology. 2011; 13:693-699.

22. Gebeshuber CA, Sladecek S and Grunert S. Beta-catenin/ LEF-1 signalling in breast cancer--central players activated by a plethora of inputs. Cells, tissues, organs. 2007; 185:5160.

23. Valenta $T$, Hausmann $G$ and Basler $K$. The many faces and functions of beta-catenin. The EMBO journal. 2012; 31:2714-2736.

24. Schade B, Lesurf R, Sanguin-Gendreau V, Bui T, Deblois G, O'Toole SA, Millar EK, Zardawi SJ, Lopez-Knowles E, Sutherland RL, Giguere V, Kahn M, Hallett M and Muller WJ. beta-Catenin signaling is a critical event in ErbB2mediated mammary tumor progression. Cancer research. 2013; 73:4474-4487.

25. Noonan EJ, Place RF, Basak S, Pookot D and Li LC. miR449a causes Rb-dependent cell cycle arrest and senescence in prostate cancer cells. Oncotarget. 2010; 1:349-358. doi: 10.18632/oncotarget.167

26. Bou Kheir T, Futoma-Kazmierczak E, Jacobsen A, Krogh A, Bardram L, Hother C, Gronbaek K, Federspiel B, Lund 
AH and Friis-Hansen L. miR-449 inhibits cell proliferation and is down-regulated in gastric cancer. Molecular cancer. 2011; 10:29.

27. Dwyer MA, Joseph JD, Wade HE, Eaton ML, Kunder RS, Kazmin D, Chang CY and McDonnell DP. WNT11 expression is induced by estrogen-related receptor alpha and beta-catenin and acts in an autocrine manner to increase cancer cell migration. Cancer research. 2010; 70:92989308.

28. Liu S, Knapp S and Ahmed AA. The structural basis of PI3K cancer mutations: from mechanism to therapy. Cancer research. 2014; 74:641-646.

29. Falasca M and Maffucci T. Role of class II phosphoinositide 3-kinase in cell signalling. Biochemical Society transactions. 2007; 35:211-214.

30. Maffucci T and Falasca M. New insight into the intracellular roles of class II phosphoinositide 3-kinases. Biochemical Society transactions. 2014; 42:1378-1382.

31. Cerami E, Gao J, Dogrusoz U, Gross BE, Sumer SO, Aksoy BA, Jacobsen A, Byrne CJ, Heuer ML, Larsson E, Antipin Y, Reva B, Goldberg AP, Sander C and Schultz $\mathrm{N}$. The cBio cancer genomics portal: an open platform for exploring multidimensional cancer genomics data. Cancer discovery. 2012; 2:401-404.

32. Gao J, Aksoy BA, Dogrusoz U, Dresdner G, Gross B, Sumer SO, Sun Y, Jacobsen A, Sinha R, Larsson E, Cerami E, Sander C and Schultz N. Integrative analysis of complex cancer genomics and clinical profiles using the cBioPortal. Science signaling. 2013; 6:pl1.

33. Kawamoto H, Koizumi $\mathrm{H}$ and Uchikoshi T. Expression of the G2-M checkpoint regulators cyclin B1 and cdc2 in nonmalignant and malignant human breast lesions: immunocytochemical and quantitative image analyses. The American journal of pathology. 1997; 150:15-23.

34. Visnjic D, Curic J, Crljen V, Batinic D, Volinia S and Banfic H. Nuclear phosphoinositide 3-kinase C2beta activation during G2/M phase of the cell cycle in HL-60 cells. Biochimica et biophysica acta. 2003; 1631:61-71.

35. Shen M, Feng Y, Gao C, Tao D, Hu J, Reed E, Li QQ and Gong J. Detection of cyclin b1 expression in $\mathrm{g}(1)$-phase cancer cell lines and cancer tissues by postsorting Western blot analysis. Cancer research. 2004; 64:1607-1610.

36. Agarwal R, Gonzalez-Angulo AM, Myhre S, Carey M, Lee JS, Overgaard J, Alsner J, Stemke-Hale K, Lluch A, Neve RM, Kuo WL, Sorlie T, Sahin A, Valero V, Keyomarsi K, Gray JW, et al. Integrative analysis of cyclin protein levels identifies cyclin b1 as a classifier and predictor of outcomes in breast cancer. Clinical cancer research. 2009; 15:36543662 .

37. Nimeus-Malmstrom E, Koliadi A, Ahlin C, Holmqvist M, Holmberg L, Amini RM, Jirstrom K, Warnberg F, Blomqvist C, Ferno M and Fjallskog ML. Cyclin B1 is a prognostic proliferation marker with a high reproducibility in a population-based lymph node negative breast cancer cohort. International journal of cancer. 2010; 127:961-967.

38. Enerly E, Steinfeld I, Kleivi K, Leivonen SK, Aure MR, Russnes HG, Ronneberg JA, Johnsen H, Navon R, Rodland E, Makela R, Naume B, Perala M, Kallioniemi O, Kristensen VN, Yakhini Z, et al. miRNA-mRNA integrated analysis reveals roles for miRNAs in primary breast tumors. PloS one. 2011; 6:e16915.

39. Yang X, Feng M, Jiang X, Wu Z, Li Z, Aau M and Yu Q. miR-449a and miR-449b are direct transcriptional targets of E2F1 and negatively regulate $\mathrm{pRb}-\mathrm{E} 2 \mathrm{~F} 1$ activity through a feedback loop by targeting CDK6 and CDC25A. Genes \& development. 2009; 23:2388-2393.

40. Ladeiro Y, Couchy G, Balabaud C, Bioulac-Sage P, Pelletier L, Rebouissou S and Zucman-Rossi J. MicroRNA profiling in hepatocellular tumors is associated with clinical features and oncogene/tumor suppressor gene mutations. Hepatology. 2008; 47:1955-1963.

41. Huang K, Zhang JX, Han L, You YP, Jiang T, Pu PY and Kang CS. MicroRNA roles in beta-catenin pathway. Molecular cancer. 2010; 9:252.

42. Wagh PK, Gray JK, Zinser GM, Vasiliauskas J, James L, Monga SP and Waltz SE. beta-Catenin is required for Ron receptor-induced mammary tumorigenesis. Oncogene. 2011; 30:3694-3704.

43. Lin SY, Xia W, Wang JC, Kwong KY, Spohn B, Wen Y, Pestell RG and Hung MC. Beta-catenin, a novel prognostic marker for breast cancer: its roles in cyclin D1 expression and cancer progression. Proceedings of the National Academy of Sciences of the United States of America. 2000; 97:4262-4266.

44. Rokavec M, Oner MG, Li H, Jackstadt R, Jiang L, Lodygin D, Kaller M, Horst D, Ziegler PK, Schwitalla S, SlottaHuspenina J, Bader FG, Greten FR and Hermeking H. IL-6R/STAT3/miR-34a feedback loop promotes EMTmediated colorectal cancer invasion and metastasis. The Journal of clinical investigation. 2014; 124:1853-1867.

45. Luo W, Huang B, Li Z, Li H, Sun L, Zhang Q, Qiu X and Wang E. MicroRNA-449a is downregulated in non-small cell lung cancer and inhibits migration and invasion by targeting c-Met. PloS one. 2013; 8:e64759.

46. Sala G, Dituri F, Raimondi C, Previdi S, Maffucci T, Mazzoletti M, Rossi C, Iezzi M, Lattanzio R, Piantelli M, Iacobelli S, Broggini $\mathrm{M}$ and Falasca M. Phospholipase Cgammal is required for metastasis development and progression. Cancer research. 2008; 68:10187-10196.

47. Raimondi C, Chikh A, Wheeler AP, Maffucci T and Falasca M. A novel regulatory mechanism links PLCgammal to PDK1. Journal of cell science. 2012; 125:3153-3163.

48. Lattanzio R, Marchisio M, La Sorda R, Tinari N, Falasca M, Alberti S, Miscia S, Ercolani C, Di Benedetto A, Perracchio L, Melucci E, Iacobelli S, Mottolese M, Natali PG, Piantelli M and Cinbo. Overexpression of activated phospholipase Cgammal is a risk factor for distant metastases in T1-T2, N0 breast cancer patients undergoing 
adjuvant chemotherapy. International journal of cancer. 2013; 132:1022-1031.

49. Moschetta M, Pretto F, Berndt A, Galler K, Richter P, Bassi A, Oliva P, Micotti E, Valbusa G, Schwager K, Kaspar M, Trachsel E, Kosmehl H, Bani MR, Neri D and Giavazzi R. Paclitaxel enhances therapeutic efficacy of the F8-IL2 immunocytokine to EDA-fibronectin-positive metastatic human melanoma xenografts. Cancer research. 2012; 72:1814-1824.
50. Kel AE, Gossling E, Reuter I, Cheremushkin E, KelMargoulis OV and Wingender E. MATCH: A tool for searching transcription factor binding sites in DNA sequences. Nucleic acids research. 2003; 31:3576-3579. 